\title{
El empleo asalariado registrado creado en la Provincia de Santa Fe por empresas del sector privado: atributos y dinámica reciente (2011-2016) Registered Salaried Employment Created in the Province of Santa Fe by Private Sector Companies: Attributes and Recent Dynamics (2011-2016) Martín Carné
}

\author{
Martín Carné es becario posdoctoral del Consejo Nacional de Investigaciones \\ Científicas y Técnicas y docente de la Universidad Nacional de Rosario, \\ Argentina. \\ E-mail: carnetes@hotmail.com
}

\section{resumen}

Con la recuperación económica iniciada en Argentina hacia 2002-2003, el incremento del empleo asalariado en general y del registrado en particular (aun estando este último lejos de exhibir niveles tolerables) opacó durante algún tiempo los debates previos sobre el "fin del trabajo" y la erosión de la relación salarial "fordista". Sin embargo, en años recientes, éstos parecerían reactualizarse con el debilitamiento del crecimiento económico y las dificultades para sostener y ampliar el nivel de empleo asalariado registrado. En este marco, utilizando datos del Sistema Integrado Previsional Argentino de la Administración Federal de Ingresos Públicos, el artículo analiza la evolución del empleo asalariado registrado privado en la Provincia de Santa Fe entre los primeros trimestres de 2011 y 2016 (discriminando los aglomerados Gran Rosario y Gran Santa Fe y las cinco regiones administrativas del territorio provincial) con el objetivo de identificar las actividades económicas y tamaños de empresa que han generado este tipo de empleo.

Se concluye que el crecimiento del empleo asalariado registrado perdió vigor en el período delimitado. Actividades administrativas y servicios de apoyo y Educación ganaron participación en la composición del empleo asalariado formal mientras que las empresas "micro", que representan el $75 \%$ de las empresas fiscalmente domiciliadas en la provincia y emplean $15 \%$ de asalariados registrados, perdieron peso en la creación de empleo en favor de las empresas "grandes", las que equivalen a algo más del $1 \%$ del total de empresas y explican casi el $40 \%$ de asalariados registrados.

\section{palabras clave}

empleo asalariado privado registrado / sistema integrado previsional argentino / provincia de Santa $\mathrm{Fe} /$ tamaño y actividad económica de empresas empleadoras

\section{summary}

With the economic recovery that began in Argentina in 2002-2003, the increase in salaried employment in general and the registered in particular (although the latter is far from tolerable levels) has overshadowed for some time the previous debates about the "end of work" and the erosion of the "fordist" wage relationship. However, in recent years, these would appear to be revived with the weakening of economic growth and the difficulties in sustaining and expanding the level of registered wage employment. Using data from the Argentine Social Security System of the Federal Public Revenue Administration, the article analyzes the evolution of private salaried and registered employment in the Province of Santa Fe between the 1st. trimester of 2011 and the same period of 2016 (discriminating Gran Rosario and Santa Fe urban agglomerates and the five administrative regions of the provincial territory) with the objective of identifying the economic activities and company sizes that have generated this type of employment. The findings indicate that the growth of this employment lost vigor in the period. Administrative activities and support services and Education gained participation in the composition of formal wage employment while "micro" companies (1-5 employees), which account for $75 \%$ of companies fiscally domiciled in the province and employ $15 \%$ of salaried and registered workers, lost percentage share in job creation in favor of "large" companies (over 100 employees), which are equivalent to just over $1 \%$ of companies and account for almost $40 \%$ of salaried and registered workers.

\section{keywords}

salaried and registered private employment / argentine integrated previsional system / Santa Fe province / size and economic activity of employer firms 


\section{Introducción}

Un sensible y destacado elemento que nutre la actual agenda pública argentina es el que refiere al nivel de empleo en particular y al estado de la situación ocupacional en general. Al señalamiento de dirigentes sindicales y legisladores nacionales opositores sobre el avance de una "ola de despidos" desde comienzos de 2016 en los sectores público y privado, las autoridades del Poder Ejecutivo Nacional argumentan que el deterioro ocupacional se manifiesta -al menos- desde los últimos cinco años, años durante los cuales, entre otros aspectos de tal escenario, no habría habido creación neta de empleo asalariado registrado.

Los asalariados constituyen la categoría ocupacional que tras la recuperación económica iniciada hacia 2002-2003 llegó a representar a algo más de siete de cada diez ocupados del país, creciendo en términos absolutos y porcentuales frente a las restantes categorías ocupacionales. Desde entonces, además, las condiciones políticas y económicas contribuyeron a que se desplegara un proceso de moderado aumento en los niveles de formalización del vínculo laboral, de positivas consecuencias para el trabajador en relación de dependencia dado el acceso a las prestaciones del Sistema de Seguridad Social (aportes jubilatorios, obra social, asignaciones familiares, vacaciones, etcétera) y que supuso, por otro lado, cierto impasse ante un clima de época hasta entonces signado por debates en torno al fin del trabajo (Rifkin, 1995), el adiós al proletariado (Gorz, 1981), la metamorfosis de la sociedad salarial (Castel, 1997) y la conveniencia de "desencantar" al empleo como articulador social (Méda, 1998).

Sin embargo, el desempeño económico menos satisfactorio de los últimos años, expresado por la evolución porcentual del Producto Interno Bruto (PIB), y algunos señalamientos de que el Estado habría acentuado su rol de empleador frente al sector privado, parecerían poner entre paréntesis esta recuperación parcial de la relación salarial clásica, reposicionando, en consecuencia, el interés por conocer cuál ha sido la dinámica reciente del empleo asalariado registrado, también llamado "típico" o "verdadero" (Busso y Pérez, 2010).

En este orden, el presente trabajo expone, desde un enfoque cuantitativo, la evolución (entre los primeros trimestres de 2011 y 2016) del empleo asalariado registrado creado por empresas del sector privado en la Provincia de Santa Fe - discriminando en su territorio las cinco regiones administrativas en que se organiza y los aglomerados urbanos Gran Rosario (GR) y Gran Santa Fe (GSF)- con el objetivo de identificar cuáles han sido las actividades económicas y los tamaños de empresa que más contribuyeron en la creación de estos puestos de trabajo (los que equivalen, ni más ni menos, que a aproximadamente el $50 \%$ del total de ocupados).

$\mathrm{Al}$ contrario de las investigaciones dedicadas a problematizar el empleo no registrado (o "informal", el cual afecta a cerca del 30\% de los asalariados), se opta aquí por la tarea menos frecuente (pero no por ello menos importante) de echar luz sobre el restante $70 \%$ de la categoría ocupacional, el cual remite a la mayoría de trabajadores que venden su fuerza de trabajo en condiciones que les permiten acceder a los derechos, garantías y protecciones que brindan los regímenes que 
componen el Sistema de Seguridad Social, dispositivo históricamente diseñado para perfilar, sino una sociedad de iguales, sí al menos una sociedad de semejantes (Castel, 2004), en la cual aquellos cuya única propiedad es, justamente, su fuerza de trabajo, puedan encontrar ciertas protecciones frente a las contingencias de la existencia y mantener relaciones de interdependencia con los demás.

La hipótesis de trabajo sostiene que en el período analizado, dados el debilitamiento de la actividad económica en el país y la provincia y la incertidumbre con respecto al control de la inflación y las decisiones económicas del gobierno asumido en diciembre de 2015, antes que destrucción de empleo asalariado registrado (práctica que conlleva costos para el empleador), en la Provincia de Santa Fe habría habido un crecimiento leve, localizado en las actividades administrativas y servicios de apoyo (que permiten un rápido ajuste del empleo en función de las fluctuaciones de la actividad económica) y en las grandes empresas, las que, entre otros aspectos, tienen menores dificultades para afrontar los costos asociados al empleo formal, registrado.

La fuente de información utilizada a tal efecto es el "Sistema de consultas de empleo privado registrado" (SC), plataforma de Internet que el Observatorio Laboral del Ministerio de Trabajo y Seguridad Social (MTySS) del Gobierno de la Provincia de Santa Fe elabora a partir de registros administrativos provenientes mensualmente del Sistema Integrado Previsional Argentino (SIPA) de la Administración Federal de Ingresos Públicos (AFIP).

El trabajo se organiza con un primer apartado en el cual se define conceptualmente en qué consiste el empleo asalariado y -en particular- el empleo asalariado registrado ante el Estado ("formal"), apuntando, antes que su retracción y/o extinción (según los debates académicos de los años '90 y comienzos de los 2000), su persistencia en coyunturas de recuperación de la actividad económica. En segundo lugar, se presentan las características de la fuente de información consultada así como sus ventajas y limitaciones. Un tercer momento traza en grueso los principales rasgos del contexto económico en el cual se inscribe la evidencia disponible, evidencia que es descripta en el cuarto apartado. Las conclusiones, por último, reúnen y analizan los hallazgos de la investigación.

\section{El empleo ${ }^{1}$ asalariado $y$ el empleo asalariado registrado: la persistencia de la relación salarial "fordista"}

La mano de obra asalariada es aquella que vende su fuerza de trabajo en el mercado y se desempeña de forma heterónoma, en relación de dependencia ${ }^{2}$ con su empleador. Aporta su trabajo personal mientras que las condiciones, instrumentos, instalaciones y maquinarias que organizan la producción le son dados (Instituto Nacional de Estadística y Censos, 2003, en adelante INDEC) por aquél. Se distingue de los patrones (quienes organizan el proceso productivo, aportan capital físico y emplean mano de obra), de los trabajadores por cuenta propia (quienes no emplean personal asalariado y utilizan su propio capital físico) y de los trabajadores familiares sin remuneración (los que, por el trabajo que realizan en el establecimiento económico que dirige un familiar, no reciben pago). 
El contrato de trabajo ${ }^{3}$ hace posible que la relación de producción que el asalariado entabla con su empleador quede regulada por la legislación laboral, la cual contribuye a definir la correlación de fuerzas ${ }^{4}$ entre ambos influyendo en a) la eficiencia del aparato productivo, sea fijando la extensión de la jornada laboral y las formas más o menos intensivas de utilización de la fuerza de trabajo y en b) la equidad social, estableciendo (o no) salarios mínimos, vacaciones pagas, aguinaldos, acceso a protecciones sociales, indemnizaciones por despido, etcétera (Cortés y Marshall, 1991).

El empleador, al dar de alta y registrar toda relación laboral ante la AFIP, permite que el trabajador asalariado acceda a los derechos y protecciones que confiere el Sistema de Seguridad Social ${ }^{5}$ : cobertura previsional, de salud y de riesgos de trabajo así como asignaciones familiares y seguro de desempleo.

Este esquema de "empleos típicos", propio de relaciones salariales "fordistas" (Neffa, 2010), en el que se apoyó la organización -desde mediados del siglo $\mathrm{XX}-$ de la integración social, sigue siendo el más extendido en el país ${ }^{6}$ no obstante el avance, en las últimas décadas, tanto del empleo asalariado no registrado ${ }^{7}$ como de diversas modalidades contractuales legales precarizantes del empleo $^{8}$ (Lindenboim, Serino y González, 2000; Feldman y Galín, 1990).

En efecto, pese a los argumentos de tipo ortodoxo que señalan que los costos que conlleva la formalización de las relaciones laborales conducen a desincentivar la inversión (afectando la creación de puestos de trabajo), a mermar la competitividad internacional por el encarecimiento de los costos laborales, a fortalecer la capacidad negociadora de los sindicatos y a resentir la productividad de los trabajadores por acogerse a los beneficios de la legislación laboral, la práctica de registrar las relaciones laborales sigue primando entre los empleadores, quienes procurarían así no sólo evitar sanciones estatales sino apostar al vínculo a largo plazo con el trabajador, su cualificación, especialización y eficiencia (Beccaria y Galín, 2002). En este sentido, entre los primeros trimestres de 2004 y 2011 (cuando inicia el período temporal aquí analizado), el porcentaje de asalariados registrados pasó del $53,8 \%$ al $65,5 \%$ en GR y del 53,6\% al 65,6\% en GSF. ${ }^{9}$ Esta evolución, muy lejos de ser satisfactoria, permite argumentar que la relación salarial "fordista" antes aludida (la que supone condiciones de subordinación, estabilidad en el puesto de trabajo, registración ante el Sistema de Seguridad Social, etcétera) no necesariamente está condenada a desaparecer sino que ella puede, no sin dificultades, persistir en función de las condiciones en que se desenvuelve la actividad económica y el rol que asume el Estado en cuanto a su promoción y protección. Aún a riesgo de resultar obvio, el crecimiento económico es la condición mayor (si bien no suficiente) para que se genere empleo (Monza, 2002) en general y asalariado registrado en particular. De aquí la conveniencia de examinar la evolución reciente de este último en años que, como se ampliará más adelante, el desempeño económico del país y la provincia alternó entre etapas de expansión y retracción. 


\section{Acerca de la fuente de información consultada}

En Argentina, las principales fuentes de información consultadas para el estudio de los mercados de trabajo urbanos son la Encuesta Permanente de Hogares (EPH), la Encuesta Anual de Hogares Urbanos (EAHU) y la Encuesta de Indicadores Laborales (EIL). Sin cuestionar sus virtudes, a los estrictos fines de describirlas y compararlas, ellas constituyen relevamientos muestrales, temporalmente estacionales y/o "puntuales" (EAHU), acotadas a ciertas actividades económicas, tamaños de unidad productiva y aglomerados urbanos (EIL) o bien aplicadas en viviendas a hogares y a población que supera determinado umbral etario $(\mathrm{EPH}$, EAHU).

En pos de complementar la información aportada por estas fuentes y refinar los diagnósticos de los mercados de trabajo locales, el MTySS de la Provincia de Santa Fe ofrece desde 2014 (a través de Internet) el denominado "Sistema de consultas de empleo privado registrado en la Provincia de Santa Fe" (SC), plataforma desde la cual se puede conocer el nivel y composición del empleo asalariado registrado creado por empresas del sector privado en distintas escalas territoriales del distrito provincial. ${ }^{10}$

Para dimensionar en términos generales el alcance de esta herramienta, si se considera que en los aglomerados GR y GSF el porcentaje de asalariados sin descuento jubilatorio se ubica en torno al $30 \%$ del total de asalariados ${ }^{11}$ y estos últimos a su vez representan, como se dijo, aproximadamente el $70 \%$ de los ocupados, la herramienta en cuestión alcanza al 50\% de ocupados totales de la provincia.

De acuerdo a la nota metodológica ubicada en el portal del SC (Provincia de Santa Fe, 2014a), éste procesa datos provenientes del Sistema Integrado Previsional Argentino (SIPA), el cual mes a mes reúne declaraciones juradas de claves únicas de identificación tributaria (CUIT) que emplean mano de obra en relación de dependencia y que informan domicilio fiscal en cualquier localidad de la Provincia de Santa Fe. ${ }^{12}$ Dichos datos se estabilizan con seis meses de retraso debido a demoras de los empleadores en presentar ante AFIP sus declaraciones juradas y/o a la posibilidad de presentar declaraciones rectificatorias de datos previamente presentados.

El SC respeta la clasificación de las actividades económicas desarrolladas por las empresas empleadoras que realiza el SIPA en base al Clasificador de Actividades Económicas (CLAE-AFIP) y, en cuanto al tamaño de las empresas, las clasifica en "micro" (hasta 5 asalariados), "pequeñas" (entre 6 y 25 asalariados), "medianas" (entre 26 y 100 asalariados) y "grandes" (más de 100 asalariados). Por último, el SC, al disponer de los códigos postales de las localidades donde las empresas se radican, informa no sólo sobre cada localidad en particular sino que también permite agruparlas en los aglomerados $\operatorname{GSF}^{13}$ y $\mathrm{GR}^{14}$ (siguiendo los criterios del INDEC), en los diecinueve distritos departamentales de la provincia y las cinco regiones administrativas trazadas ${ }^{15}$ por el Plan Estratégico Provincial (PEP). ${ }^{16}$

Por lo expuesto, y aun con las limitaciones apuntadas, el SC constituye un aporte a la disponibilidad de información con que estudiar la situación ocupacional pro- 
vincial. Este aporte se potencia además si se considera que a lo largo del presente año el INDEC todavía no hizo pública la información brindada por la EPH.

\section{El contexto económico nacional y provincial en el período 2011- 2016}

Hay un extendido acuerdo (Centro de Estudios para el Desarrollo Argentino, 2012; Schorr, 2012; Damill y Frenkel, 2015; Kulfas, 2016) en que para 2011, el aparato productivo (en cuyo marco se crean las ocupaciones laborales, entre ellas, por supuesto, las asalariadas registradas), no mostraba el satisfactorio desempeño exhibido al menos entre 2003 y 2007. En efecto, hacia aquel año (y los subsiguientes) el PIB ya no crecía en torno al $9 \%$ promedio anual observado con anterioridad $^{17}$, los superávits fiscal y comercial se habían debilitado, el persistente aumento de precios internos ${ }^{18}$ afectaba la competitividad del tipo de cambio y de las exportaciones, las reservas del Banco Central -por fuga de divisas- se alejaban del techo de 50 mil millones de dólares alcanzado en 2010 (reintroduciendo el viejo problema de la restricción externa) y los precios de los commodities se desinflaron con respecto a años previos ${ }^{19}$, resintiendo así la recaudación tributaria (derechos a las exportaciones) y la obtención de divisas con las que intervenir en el mercado cambiario.

En el mercado de trabajo, el desempleo encontraba dificultades para perforar el piso del 6\%-7\%. Entre los primeros trimestres de 2011 y 2015, los asalariados empleados por el Estado pasaron del 21,1\% al 23,1\% (un crecimiento del 9,5\%) y los cuentapropistas aumentaron un punto porcentual su participación entre los ocupados a expensas de los patrones. ${ }^{20}$ Información elaborada por el Observatorio de la Deuda Social Argentina de la Universidad Católica Argentina (2016, en adelante UCA) señala que entre 2010 y 2015 la incidencia de los trabajadores del sector micro-informal (patrones y asalariados de pequeñas empresas, cuenta propias no profesionales, trabajadores domésticos o familiares) en el total de ocupados alcanzó el 53,9\% y que si bien "el empleo total se expandió $8 \%$, se incrementó sólo 3\% la cantidad de puestos de trabajo con empleo pleno de derechos" (UCA, 2016: 2).

Entre los antecedentes que explican este desempeño pueden mencionarse factores de orden externo e interno. De los primeros, la crisis financiera internacional ${ }^{21}$ iniciada hacia mediados de 2007 impactó a nivel de fuga de capitales privados y reducción del comercio exterior. La recesión de Brasil - principal socio comercial de Argentina- iniciada a fines de 2014, también contribuyó a recortar la demanda de bienes nacionales. En cuanto a factores internos, el conflicto con actores del sector agropecuario por la (finalmente trunca) fijación de alícuotas móviles en concepto de derechos de exportación sobre soja, trigo y maíz, tuvo como consecuencia un incremento del precio de los bienes mientras que la política de subsidios a las tarifas de los servicios públicos disparó el gasto estatal muy por encima del nivel de recursos, acentuando el déficit fiscal.

Frente a este escenario, el gobierno nacional reelecto en 2011 instrumentó con éxito variable políticas públicas tendientes a fomentar las exportaciones (Progra- 
ma de Aumento y Diversificación de Exportaciones), el consumo interno (Precios Cuidados, Programa de Crédito Argentino del Bicentenario para la Vivienda Única Familiar) y la inversión (Fondo Nacional para el Desarrollo y Fortalecimiento de las Micro, Pequeñas y Medianas Empresas, Programa de Acceso al Crédito y la Competitividad) para apuntalar el nivel de empleo. El cumplimiento de este objetivo también se alentó con la sanción de la ley $N^{\circ} 26.940 / 14$, la que ofreció a los empleadores incentivos impositivos para reducir costos laborales asociados a la incorporación de nuevos trabajadores o bien a la regularización de trabajadores de hecho en relación de dependencia.

Con respecto al gobierno que asumió en diciembre de 2015, las principales medidas de política económica que implementó argumentando promover la reactivación de la economía y el crecimiento del empleo fueron la devaluación de la moneda y la unificación del tipo de cambio, la eliminación y reducción de derechos de exportación para la minería, la ganadería y la agricultura, la flexibilización de las importaciones y la devolución de parte del Impuesto al Valor Agregado en las compras de jubilados y beneficiarios de la Asignación Universal por Hijo.

Por su parte, la provincia de Santa Fe, área económicamente abierta y por ende no ajena a los procesos y tendencias característicos de la economía nacional, atravesó años cuyo Producto Bruto Geográfico (PBG) presentó una tendencia decreciente: $8 \%$ de crecimiento en $2011,0,9 \%$ en $2012,4,9 \%$ en $2013,3,3 \%$ en 2014 y $2,9 \%$ en 2015 (Provincia de Santa Fe, 2016a). De estructura productiva diversificada ${ }^{22}$, en los años señalados las actividades tambera, frigorífica, automotriz, autopartista, metalmecánica y del biodiesel fueron particularmente resentidas por la caída de exportaciones a Brasil y Europa (Federación Industrial de Santa Fe, 2014), multiplicándose los procedimientos preventivos de crisis iniciados por empleadores. En estos casos, una práctica habitual fue la de gestionar ante el MTEySS la aplicación del Programa de Recuperación Productiva (REPRO), el cual "brinda a los trabajadores de las empresas adheridas una suma fija mensual remunerativa hasta el monto equivalente al salario mínimo, vital y móvil actualizado a la fecha de otorgamiento y por un plazo de hasta 12 meses, destinada a completar el sueldo de su categoría laboral, mediante el pago directo por la Administración Nacional de la Seguridad Social" (MTEySS, 2016). ${ }^{23}$

Por último (y para una mejor comprensión de los próximos apartados), las actividades económicas que históricamente han distinguido a los aglomerados GR y GSF en cuanto a creación de empleo asalariado son, para el primero, las actividades industriales (en buena parte ligadas al procesamiento de materias primas producidas en la región) y también las de servicios de transporte y almacenamiento, enseñanza y alojamiento y servicio de comidas. En lo que respecta a GSF, este aglomerado se ha caracterizado por una estructura productiva en la que han prevalecido las actividades terciarias (Comercio principalmente y el agregado de servicios públicos y privados) por sobre las industriales y agropecuarias. Siendo la ciudad de Santa Fe capital político-administrativa de la provincia, en el aglomerado el Estado (municipal, provincial y nacional) se destaca como uno de los princi- 
pales empleadores. De hecho, el empleo público pasó de 32,2\% a 30,8\% entre los primeros trimestres de 2011 y 2015 , valores que en GR fueron $13,8 \%$ y $16,2 \%{ }^{24}$

\section{Análisis de la evidencia}

\subsection{La situación en el agregado provincial y en los aglomerados Gran Rosario y Gran Santa Fe}

El Gráfico $\mathrm{N}^{\circ} 1$ permite dimensionar la magnitud de la población asalariada formal de la provincia y de los aglomerados GR y GSF así como también su evolución. En términos absolutos, ella creció trimestre a trimestre con la única excepción de GR entre 2013 y 2014, cuando perdió 898 puestos de trabajo. A nivel provincial, en el $1^{\circ}$ trimestre de 2016 hubo 28.324 ocupaciones más que en igual período de 2011, en GR 14.753 y en GSF, 9.103. Para ese mismo período, GR representó casi el 50\% del total de empleo asalariado registrado en la provincia mientras que GSF alcanzó el 14,8\%. No obstante esta sensible diferencia en el tamaño de los aglomerados, ponderando las puntas 2011-2016, GSF mostró ser más dinámico en la creación de empleo asalariado formal: allí se expandió 14,3\% mientras que en GR lo hizo en $6,4 \%$, más en línea con el crecimiento porcentual del agregado provincial $(6,1 \%)$.

\section{Gráfico $\mathrm{N}^{0} 1$. Nivel de empleo asalariado registrado por empresas del sector privado. Provincia de Santa Fe y aglomerados urbanos Gran Santa Fe y Gran Rosario. $1^{\circ}$ trimestre $2011-1^{\circ}$ trimestre 2016}

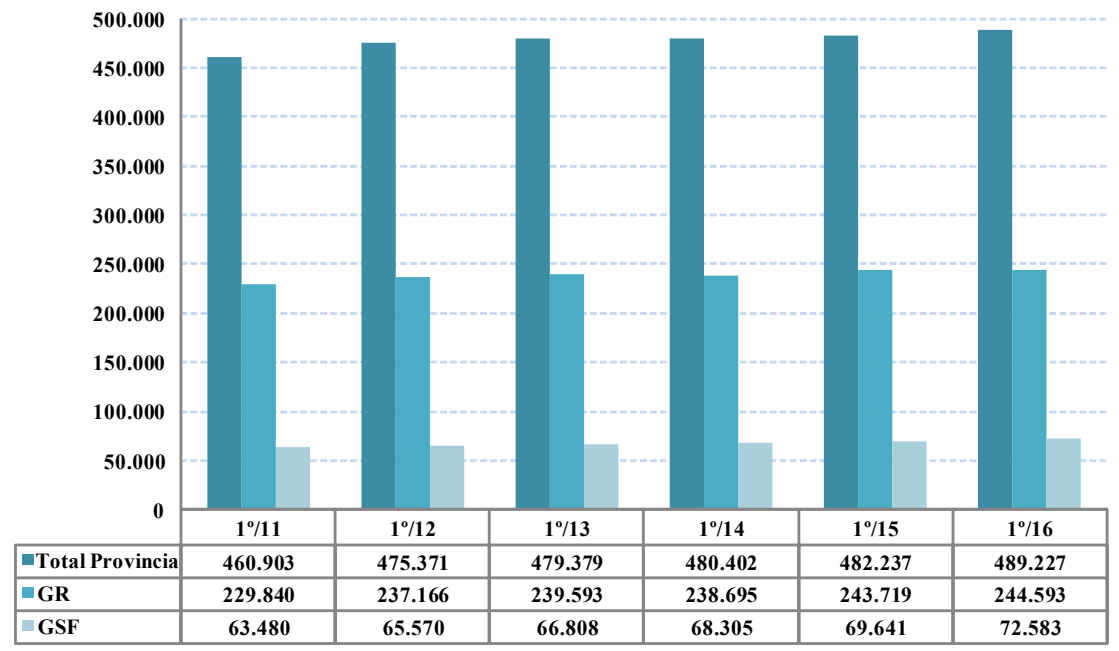

Fuente: Elaboración propia en base a MTySS de la Provincia de Santa Fe / SIPA. 
Presentando las variaciones porcentuales interanuales del empleo asalariado registrado, del Gráfico $\mathrm{N}^{\circ} 2$ se desprende cómo su creación fue gradualmente perdiendo intensidad. El agregado provincial recién en 2016 volvió a crecer en una magnitud superior al dígito (1,4\%), hecho no observado desde 2012. GSF, a pesar de la merma observada, fue el ámbito territorial de mayor crecimiento (y comportamiento más independiente que el del agregado provincial y GR), hecho particularmente notorio en 2016 (4,2\%). Puede hipotetizarse que este fenómeno se correlaciona con la relativamente más alta participación de empleo público en el empleo registrado total que presenta el aglomerado, lo cual, por la estabilidad y continuidad de ingresos (salarios) que supone para parte de la demanda, le confiere cierta autonomía con respecto al comportamiento provincial y de GR. Éste, a su vez, recuperó en 2015 la caída del año anterior pero en 2016 creció en forma moderada $(0,4 \%)$. La performance del aglomerado entre 2011 y 2014 acompañó en tendencia a la del total provincial pero a partir de ese año sus evoluciones dejaron de converger. Las causas pueden rastrearse en la complicada coyuntura que atravesaron los tambos, frigoríficos y establecimientos metalmecánicos localizados en el interior provincial.

\section{Gráfico $\mathbf{N}^{0}$ 2. Variación porcentual del empleo asalariado registrado por empresas del sector privado. Provincia de Santa Fe y aglomerados urbanos Gran Santa Fe y Gran Rosario. $1^{\circ}$ trimestre 2011 - $1^{\circ}$ trimestre 2016}

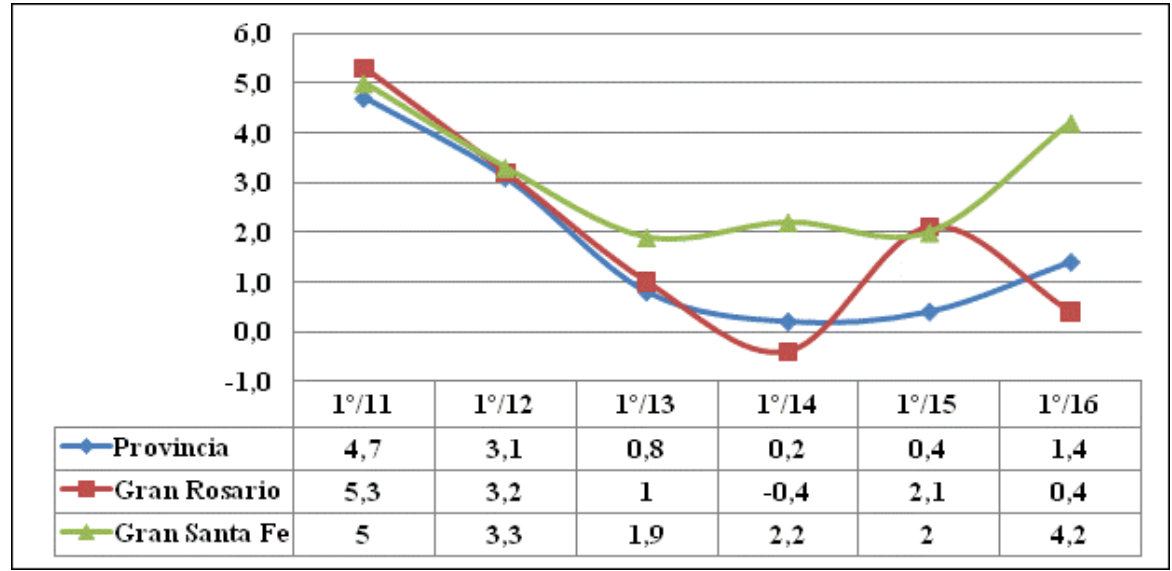

Fuente: Elaboración propia en base a MTySS de la Provincia de Santa Fe / SIPA.

En cuanto a la distribución del empleo asalariado registrado según sector de actividad económica, las Tablas 1, 2 y 3 (agregado provincial, GR y GSF respectivamente) presentan la participación porcentual de cada actividad en el total del empleo formal creado. En el $1^{\circ}$ trimestre de 2016, a nivel provincial, la principal actividad empleadora fue Industria manufacturera, la que explicó la cuarta parte 
del empleo asalariado registrado (si bien perdió 3,1\% de participación en el período delimitado). Le siguió Comercio con casi el $20 \%$ de ocupaciones asalariadas registradas, Enseñanza $(7,7 \%)$ y Servicios de transporte y almacenamiento (7,4\%). En el análisis, debe destacarse que además de la mencionada caída de la Industria manufacturera, mejoraron su participación relativa Enseñanza (16,6\%) y Actividades administrativas y servicios de apoyo $(9,4 \%)$.

\section{Tabla $\mathbf{N}^{0} 1$. Distribución porcentual del empleo asalariado registrado por empresas del sector privado según sector de actividad económica. \\ Provincia de Santa Fe. $1^{\circ}$ trimestre $2011-1^{\circ}$ trimestre 2016}

\begin{tabular}{|c|c|c|c|c|c|c|}
\hline \multicolumn{7}{|c|}{ Total Provincia de Santa Fe } \\
\hline Actividades económicas & $1^{0} / 11$ & $1^{\circ} / 12$ & $1^{0} / 13$ & $1^{\circ} / 14$ & $1^{0} / 15$ & $1^{\circ} / 16$ \\
\hline Datos sin especificar & 0,3 & 0,4 & 0,1 & 0,1 & 0,2 & 0,3 \\
\hline $\begin{array}{l}\text { Agricultura, ganadería, } \\
\text { caza, silvicultura y pesca }\end{array}$ & 5,3 & 5,5 & 5,4 & 5,1 & 5,0 & 4,7 \\
\hline $\begin{array}{l}\text { Explotación de minas y } \\
\text { canteras }\end{array}$ & 0,1 & 0,1 & 0,1 & 0,1 & 0,1 & 0,1 \\
\hline Industria manufacturera & 25,4 & 25,1 & 24,8 & 25,0 & 24,3 & 24,6 \\
\hline $\begin{array}{l}\text { Suministro de electricidad, } \\
\text { gas, vapor y aire acondi- } \\
\text { cionado }\end{array}$ & 0,7 & 0,7 & 0,7 & 0,7 & 0,7 & 0,7 \\
\hline $\begin{array}{l}\text { Suministro de agua, cloa- } \\
\text { cas y gestión de residuos }\end{array}$ & 1,0 & 1,0 & 1,0 & 1,1 & 1,1 & 1,1 \\
\hline Construcción & 7,0 & 7,2 & 6,7 & 6,7 & 6,9 & 6,6 \\
\hline $\begin{array}{l}\text { Comercio al por mayor y } \\
\text { al por menor }\end{array}$ & 19,6 & 19,6 & 19,5 & 19,7 & 19,3 & 19,5 \\
\hline $\begin{array}{l}\text { Servicio de transporte y } \\
\text { almacenamiento }\end{array}$ & 7,1 & 7,1 & 7,1 & 7,2 & 7,5 & 7,4 \\
\hline $\begin{array}{l}\text { Servicios de alojamiento y } \\
\text { servicios de comida }\end{array}$ & 2,7 & 2,7 & 2,8 & 2,8 & 2,8 & 2,7 \\
\hline $\begin{array}{l}\text { Información y comunica- } \\
\text { ciones }\end{array}$ & 1,7 & 1,7 & 1,9 & 1,9 & 2,0 & 2,0 \\
\hline $\begin{array}{l}\text { Intermediación financiera } \\
\text { y servicios de seguros }\end{array}$ & 2,5 & 2,6 & 2,7 & 2,9 & 2,5 & 2,5 \\
\hline Servicios inmobiliarios & 0,7 & 0,7 & 0,8 & 0,8 & 0,7 & 0,7 \\
\hline $\begin{array}{l}\text { Servicios profesionales, } \\
\text { científicos y técnicos }\end{array}$ & 1,8 & 1,9 & 1,9 & 2,0 & 1,8 & 1,8 \\
\hline $\begin{array}{l}\text { Actividades administrati- } \\
\text { vas y servicios de apoyo }\end{array}$ & 6,4 & 6,3 & 6,7 & 6,4 & 7,0 & 7,0 \\
\hline Enseñanza & 6,6 & 6,4 & 6,6 & 6,9 & 7,5 & 7,7 \\
\hline $\begin{array}{l}\text { Salud humana y servicios } \\
\text { sociales }\end{array}$ & 4,2 & 4,2 & 4,3 & 4,3 & 4,3 & 4,3 \\
\hline
\end{tabular}




\begin{tabular}{|l|c|c|c|c|c|c|}
\hline $\begin{array}{l}\text { Servicios artísticos, cul- } \\
\text { turales, deportivos y de } \\
\text { esparcimiento }\end{array}$ & 1,5 & 1,5 & 1,5 & 1,5 & 1,5 & 1,5 \\
\hline $\begin{array}{l}\text { Servicios de asociaciones } \\
\text { y servicios personales }\end{array}$ & 5,4 & 5,3 & 5,4 & 4,8 & 4,8 & 4,8 \\
\hline $\begin{array}{l}\text { Servicios de organizacio- } \\
\text { nes y órganos extraterri- } \\
\text { toriales }\end{array}$ & 0,0 & 0,0 & 0,0 & 0,0 & 0,0 & 0,0 \\
\hline Total & $\mathbf{1 0 0 , 0}$ & $\mathbf{1 0 0 , 0}$ & $\mathbf{1 0 0 , 0}$ & $\mathbf{1 0 0 , 0}$ & $\mathbf{1 0 0 , 0}$ & $\mathbf{1 0 0 , 0}$ \\
\hline
\end{tabular}

Fuente: Elaboración propia en base a MTySS de la Provincia de Santa Fe / SIPA.

Tabla $\mathbf{N}^{0} 2$. Distribución porcentual del empleo asalariado registrado por empresas del sector privado según sector de actividad económica. Aglomerado Gran Rosario. $1^{\circ}$ trimestre $2011-1^{\circ}$ trimestre 2016

\begin{tabular}{|l|c|c|c|c|c|c|}
\hline \multicolumn{7}{|c|}{ Gran Rosario } \\
\hline Actividades económicas & $\mathbf{1}^{\mathbf{0}} / \mathbf{1 1}$ & $\mathbf{1}^{\mathbf{0}} / \mathbf{1 2}$ & $\mathbf{1}^{\mathbf{0}} / \mathbf{1 3}$ & $\mathbf{1}^{\mathbf{0}} / \mathbf{1 4}$ & $\mathbf{1}^{\mathbf{0}} / \mathbf{1 5}$ & $\mathbf{1}^{\mathbf{0}} / \mathbf{1 6}$ \\
\hline Datos sin especificar & 0,3 & 0,3 & 0,1 & 0,1 & 0,1 & 0,1 \\
\hline $\begin{array}{l}\text { Agricultura, ganadería, } \\
\text { caza, silvicultura y pesca }\end{array}$ & 1,7 & 1,8 & 1,8 & 1,8 & 1,7 & 1,9 \\
\hline $\begin{array}{l}\text { Explotación de minas y } \\
\text { canteras }\end{array}$ & 0,1 & 0,1 & 0,1 & 0,1 & 0,1 & 0,1 \\
\hline Industria manufacturera & 20,7 & 20,4 & 20,1 & 20,1 & 19,7 & 19,9 \\
\hline $\begin{array}{l}\text { Suministro de electricidad, } \\
\text { gas, vapor y aire } \\
\text { acondicionado }\end{array}$ & 0,9 & 0,9 & 0,9 & 0,9 & 1,0 & 1,0 \\
\hline $\begin{array}{l}\text { Suministro de agua, } \\
\text { cloacas y gestión de } \\
\text { residuos }\end{array}$ & 1,0 & 1,0 & 1,1 & 1,1 & 1,2 & 1,2 \\
\hline Construcción & 9,5 & 9,6 & 9,0 & 9,0 & 9,0 & 8,5 \\
\hline $\begin{array}{l}\text { Comercio al por mayor y } \\
\text { al por menor }\end{array}$ & 17,7 & 17,5 & 17,5 & 17,7 & 17,1 & 17,2 \\
\hline $\begin{array}{l}\text { Servicio de transporte y } \\
\text { almacenamiento }\end{array}$ & 8,7 & 8,7 & 8,6 & 8,6 & 8,6 & 8,6 \\
\hline $\begin{array}{l}\text { Servicios de alojamiento y } \\
\text { servicios de comida }\end{array}$ & 3,6 & 3,6 & 3,7 & 3,8 & 3,7 & 3,7 \\
\hline $\begin{array}{l}\text { Información y } \\
\text { comunicaciones }\end{array}$ & 2,4 & 2,5 & 2,7 & 2,8 & 2,9 & 3,0 \\
\hline $\begin{array}{l}\text { Intermediación financiera } \\
\text { y servicios de seguros }\end{array}$ & 1,9 & 2,0 & 1,9 & 2,1 & 2,0 & 1,7 \\
\hline
\end{tabular}




\begin{tabular}{|l|c|c|c|c|c|c|}
\hline Servicios inmobiliarios & 0,9 & 1,0 & 1,1 & 1,0 & 0,8 & 0,8 \\
\hline $\begin{array}{l}\text { Servicios profesionales, } \\
\text { científicos y técnicos }\end{array}$ & 1,7 & 1,8 & 1,8 & 1,9 & 1,8 & 1,8 \\
\hline $\begin{array}{l}\text { Actividades } \\
\text { administrativas y servicios } \\
\text { de apoyo }\end{array}$ & 10,4 & 10,4 & 10,8 & 10,3 & 11,4 & 11,4 \\
\hline Enseñanza & 6,4 & 6,4 & 6,5 & 6,9 & 7,2 & 7,4 \\
\hline $\begin{array}{l}\text { Salud humana y servicios } \\
\text { sociales }\end{array}$ & 5,0 & 5,1 & 5,3 & 5,4 & 5,3 & 5,3 \\
\hline $\begin{array}{l}\text { Servicios artísticos, } \\
\text { culturales, deportivos y de } \\
\text { esparcimiento }\end{array}$ & 2,0 & 2,0 & 2,0 & 2,0 & 2,0 & 2,0 \\
\hline $\begin{array}{l}\text { Servicios de asociaciones y } \\
\text { servicios personales }\end{array}$ & 5,1 & 4,9 & 5,0 & 4,4 & 4,4 & 4,4 \\
\hline $\begin{array}{l}\text { Servicios de } \\
\text { organizaciones y órganos } \\
\text { extraterritoriales }\end{array}$ & 0,0 & 0,0 & 0,0 & 0,0 & 0,0 & 0,0 \\
\hline & $\mathbf{1 0 0 , 0}$ & $\mathbf{1 0 0 , 0}$ & $\mathbf{1 0 0 , 0}$ & $\mathbf{1 0 0 , 0}$ & $\mathbf{1 0 0 , 0}$ & $\mathbf{1 0 0 , 0}$ \\
\hline Total & & & & & \\
\hline
\end{tabular}

Fuente: Elaboración propia en base a MTySS de la Provincia de Santa Fe / SIPA.

En GR, también Industria manufacturera $(19,9 \%)$ y Comercio $(17,2 \%)$ fueron las principales actividades empleadoras aunque con porcentajes inferiores a los observados para el total provincial, lo que se debe al mayor peso relativo de los servicios en su aparato productivo. En tercer lugar se ubicó Actividades administrativas y servicios de apoyo (la que mejoró su participación 9,6\% durante el período) y en cuarto, Construcción ( $8,5 \%$ ), la que perdió un $10 \%$ de participación entre puntas del período. La pérdida de participación de la Industria fue del 3,8\%. Debe destacarse que entre las Actividades administrativas y servicios de apoyo se cuentan servicios como obtención y dotación de personal, servicios de seguridad, de limpieza de edificios, de call center, de jardinería y mantenimiento de espacios verdes, entre otros (Provincia de Santa Fe, 2014b), los cuales ofrecen al contratante la posibilidad de un rápido ajuste de su demanda vis à vis las oscilaciones de la actividad económica.

En GSF, Comercio empleó casi el 25\% del total de asalariados registrados seguido por Industria manufacturera (13\%), Enseñanza $(11,6 \%)$ y Servicios de asociaciones y servicios personales (8,8\%). En el período, la Industria perdió 10,3\% de participación en la composición del empleo asalariado registrado mientras que Transporte y almacenamiento, Actividades administrativas y servicios de apoyo y Enseñanza ganaron $37,5 \%, 18,4 \%$ y $8,4 \%$ respectivamente. 
Tabla $\mathbf{N}^{0} 3$. Distribución porcentual del empleo asalariado registrado por empresas del sector privado según sector de actividad económica. Aglomerado Gran Santa Fe. $1^{\circ}$ trimestre $2011-1^{\circ}$ trimestre 2016

\begin{tabular}{|c|c|c|c|c|c|c|}
\hline \multicolumn{7}{|c|}{ Gran Santa Fe } \\
\hline Actividades económicas & $1^{\circ} / 11$ & $1^{\circ} / 12$ & $1^{\circ} / 13$ & $1^{\circ} / 14$ & $1^{0} / 15$ & $1^{\circ} / 16$ \\
\hline Datos sin especificar & 0,4 & 0,2 & 0,2 & 0,2 & 0,2 & 1,1 \\
\hline $\begin{array}{l}\text { Agricultura, ganadería, caza, } \\
\text { silvicultura y pesca }\end{array}$ & 1,9 & 2,2 & 2,2 & 2,1 & 1,9 & 2,0 \\
\hline $\begin{array}{l}\text { Explotación de minas y } \\
\text { canteras }\end{array}$ & 0,2 & 0,2 & 0,2 & 0,1 & 0,1 & 0,1 \\
\hline Industria manufacturera & 14,5 & 13,9 & 13,9 & 14,2 & 13,6 & 13,0 \\
\hline $\begin{array}{l}\text { Suministro de electricidad, } \\
\text { gas, vapor y aire } \\
\text { acondicionado }\end{array}$ & 0,0 & 0,0 & 0,0 & 0,0 & 0,0 & 0,0 \\
\hline $\begin{array}{l}\text { Suministro de agua, cloacas } \\
\text { y gestión de residuos }\end{array}$ & 2,4 & 2,5 & 2,4 & 2,3 & 2,3 & 2,2 \\
\hline Construcción & 7,7 & 8,1 & 7,4 & 7,3 & 7,5 & 8,0 \\
\hline $\begin{array}{l}\text { Comercio al por mayor y al } \\
\text { por menor }\end{array}$ & 24,3 & 25,2 & 24,8 & 24,6 & 23,7 & 23,4 \\
\hline $\begin{array}{l}\text { Servicio de transporte y } \\
\text { almacenamiento }\end{array}$ & 5,6 & 5,4 & 5,5 & 7,0 & 8,2 & 7,7 \\
\hline $\begin{array}{l}\text { Servicios de alojamiento y } \\
\text { servicios de comida }\end{array}$ & 3,4 & 3,4 & 3,5 & 3,3 & 3,3 & 3,2 \\
\hline $\begin{array}{l}\text { Información y } \\
\text { comunicaciones }\end{array}$ & 1,7 & 1,6 & 1,6 & 1,3 & 1,3 & 1,1 \\
\hline $\begin{array}{l}\text { Intermediación financiera y } \\
\text { servicios de seguros }\end{array}$ & 4,8 & 4,8 & 4,8 & 4,7 & 4,6 & 4,5 \\
\hline Servicios inmobiliarios & 0,8 & 0,9 & 0,9 & 0,9 & 0,9 & 1,0 \\
\hline $\begin{array}{l}\text { Servicios profesionales, } \\
\text { científicos y técnicos }\end{array}$ & 1,8 & 1,9 & 1,9 & 1,7 & 1,6 & 1,5 \\
\hline $\begin{array}{l}\text { Actividades administrativas } \\
\text { y servicios de apoyo }\end{array}$ & 3,8 & 3,4 & 4,1 & 4,0 & 4,1 & 4,5 \\
\hline Enseñanza & 10,7 & 10,3 & 10,3 & 10,9 & 11,4 & 11,6 \\
\hline $\begin{array}{l}\text { Salud humana y servicios } \\
\text { sociales }\end{array}$ & 5,1 & 5,2 & 5,1 & 4,9 & 4,8 & 4,7 \\
\hline $\begin{array}{l}\text { Servicios artísticos, } \\
\text { culturales, deportivos y de } \\
\text { esparcimiento }\end{array}$ & 1,8 & 1,8 & 1,7 & 1,6 & 1,6 & 1,6 \\
\hline $\begin{array}{l}\text { Servicios de asociaciones y } \\
\text { servicios personales }\end{array}$ & 9,1 & 9,0 & 9,5 & 8,9 & 8,9 & 8,8 \\
\hline $\begin{array}{l}\text { Servicios de organizaciones } \\
\text { y órganos extraterritoriales }\end{array}$ & 0,0 & 0,0 & 0,0 & 0,0 & 0,0 & 0,0 \\
\hline Total & 100,0 & 100,0 & 100,0 & 100,0 & 100,0 & 100,0 \\
\hline
\end{tabular}


Según la variable tamaño de las empresas (Tabla $\mathrm{N}^{\circ} 4$ ), en el agregado provincial ( $1^{\circ}$ trimestre de 2016), del total de ellas (39.923 empresas), 76,3\% calificó como "micro" (entre 1 y 5 puestos de trabajo) y empleó al 15,4\% del empleo asalariado registrado (75.350 trabajadores) mientras que apenas un 1,2\% de empresas (603 en valores absolutos) calificó como "grande" (más de 100 puestos de trabajo) empleando al 38,1\% de asalariados registrados (186.458 trabajadores). En comparación con igual período de 2011, se observa la tendencia de que disminuye el porcentaje de empresas "micro" y crece el de las "grandes" mientras que el empleo se concentra en estas últimas en desmedro de las restantes. En GR y GSF esta situación se reproduce para peor: allí las empresas "grandes" toman 42,6\% y $43,3 \%$ del empleo asalariado formal mientras que cinco años antes absorbían $39,1 \%$ y $36,8 \%$ respectivamente (variación porcentual de $8,9 \%$ y $17,6 \%$ ). Este cambio pone de manifiesto las mayores dificultades que afrontan las empresas de menor tamaño para sostener el empleo registrado, sobre todo en situaciones de incertidumbre con respecto al devenir de la producción.

Tabla $N^{\circ} 4$. Distribución porcentual de empresas del sector privado y asalariados registrados según tamaño de la empresa. Provincia de Santa Fe y aglomerados urbanos Gran Santa Fe y Gran Rosario. $1^{\circ}$ trimestre $2011-1^{\circ}$ trimestre 2016

\begin{tabular}{|c|c|c|c|c|c|c|c|c|c|c|c|c|}
\hline \multicolumn{7}{|c|}{$1^{\circ}$ trimestre 2011} & \multicolumn{6}{|c|}{$1^{\circ}$ trimestre 2016} \\
\hline Tamaño & $\begin{array}{c}\text { Provin- } \\
\text { cia }\end{array}$ & $\begin{array}{c}\text { Puestos } \\
\text { de tra- } \\
\text { bajo }\end{array}$ & $\begin{array}{c}\text { Gran } \\
\text { Rosario }\end{array}$ & $\begin{array}{c}\text { Puestos de } \\
\text { trabajo }\end{array}$ & $\begin{array}{c}\text { Gran } \\
\text { Santa } \\
\text { Fe }\end{array}$ & $\begin{array}{c}\text { Pues- } \\
\text { tos de } \\
\text { trabajo }\end{array}$ & $\begin{array}{c}\text { Provin- } \\
\text { cia }\end{array}$ & $\begin{array}{c}\text { Puestos } \\
\text { de tra- } \\
\text { bajo }\end{array}$ & $\begin{array}{c}\text { Gran } \\
\text { Rosario }\end{array}$ & $\begin{array}{c}\text { Puestos } \\
\text { de tra- } \\
\text { bajo }\end{array}$ & $\begin{array}{c}\text { Gran } \\
\text { Santa } \\
\text { Fe }\end{array}$ & $\begin{array}{c}\text { Puestos } \\
\text { de tra- } \\
\text { bajo }\end{array}$ \\
\hline $\begin{array}{l}\text { Micro- } \\
\text { empresas } \\
(1-5 \\
\text { asalaria- } \\
\text { dos })\end{array}$ & 77,0 & 17,2 & 72,7 & 13,6 & 75,0 & 15,9 & 76,3 & 15,4 & 72,1 & 12,3 & 74,6 & 13,4 \\
\hline $\begin{array}{l}\text { Pequeñas } \\
\text { empresas } \\
(6-25 \\
\text { asalaria- } \\
\text { dos })\end{array}$ & 17,3 & 22,4 & 20,1 & 21,6 & 18,8 & 22,2 & 17,5 & 21,1 & 20,2 & 20,3 & 18,6 & 19,2 \\
\hline $\begin{array}{l}\text { Medianas } \\
\text { empresas } \\
(26-100 \\
\text { asalaria- } \\
\text { dos })\end{array}$ & 4,7 & 25,3 & 5,8 & 25,7 & 4,9 & 25,1 & 5,0 & 25,4 & 6,2 & 24,8 & 5,2 & 24,1 \\
\hline $\begin{array}{l}\begin{array}{l}\text { Grandes } \\
\text { empresas } \\
\text { (Más de }\end{array} \\
100 \text { asala- } \\
\text { riados) }\end{array}$ & 1,0 & 35,1 & 1,4 & 39,1 & 1,3 & 36,8 & 1,2 & 38,1 & 1,5 & 42,6 & 1,6 & 43,3 \\
\hline Total & 100,0 & 100,0 & 100,0 & 100,0 & 100,0 & 100,0 & 100,0 & 100,0 & 100,0 & 100,0 & 100,0 & 100,0 \\
\hline
\end{tabular}

Fuente: Elaboración propia en base a MTySS de la Provincia de Santa Fe / SIPA. 


\subsection{El panorama a nivel de las regiones administrativas}

Sin perjuicio de los diecinueve distritos departamentales existentes, las autoridades del Poder Ejecutivo Provincial electas en 2007 promovieron una nueva territorialidad para gobernar la provincia delimitando a tal efecto las regiones 1 (Nodo Reconquista), 2 (Nodo Rafaela), 3 (Nodo Santa Fe), 4 (Nodo Rosario) y 5 (Nodo Venado Tuerto) y así reorganizar e integrar territorios anteriormente desconectados y equilibrar las capacidades del Estado en toda la provincia (Provincia de Santa Fe, 2008).

El Gráfico $\mathrm{N}^{\circ} 3$ presenta la cantidad de asalariados registrados de empresas privadas con que cuenta cada una de las cinco regiones con respecto al total provincial. Para el $1^{\circ}$ trimestre de 2016, la Región 4 equivalió al 60,5\% del empleo asalariado registrado de la provincia (sumando 15.369 puestos de trabajo más a los observados en el comienzo de la serie), seguida por la Región 3 (20,5\% y 9.783 nuevos puestos), la Región 2 (9,2\% y 1.078 puestos) y las regiones 1 y 5 con el $4,9 \%$ cada una (2.589 puestos más y 556 puestos menos respectivamente). Esta composición porcentual no varió de modo significativo con respecto a igual período de 2011 si bien se destaca que la Región 3 aumentó su participación relativa $(4,4 \%)$ y las regiones 2,4 y 5 la disminuyeron $(3,5 \%, 0,6 \%$ y $8 \%$ respectivamente).

\section{Gráfico $\mathbf{N}^{\circ} 3$. Nivel de empleo asalariado registrado por empresas del sector privado. Provincia de Santa Fe y regiones administrativas. $1^{\circ}$ trimestre $2011-1^{\circ}$ trimestre 2016}

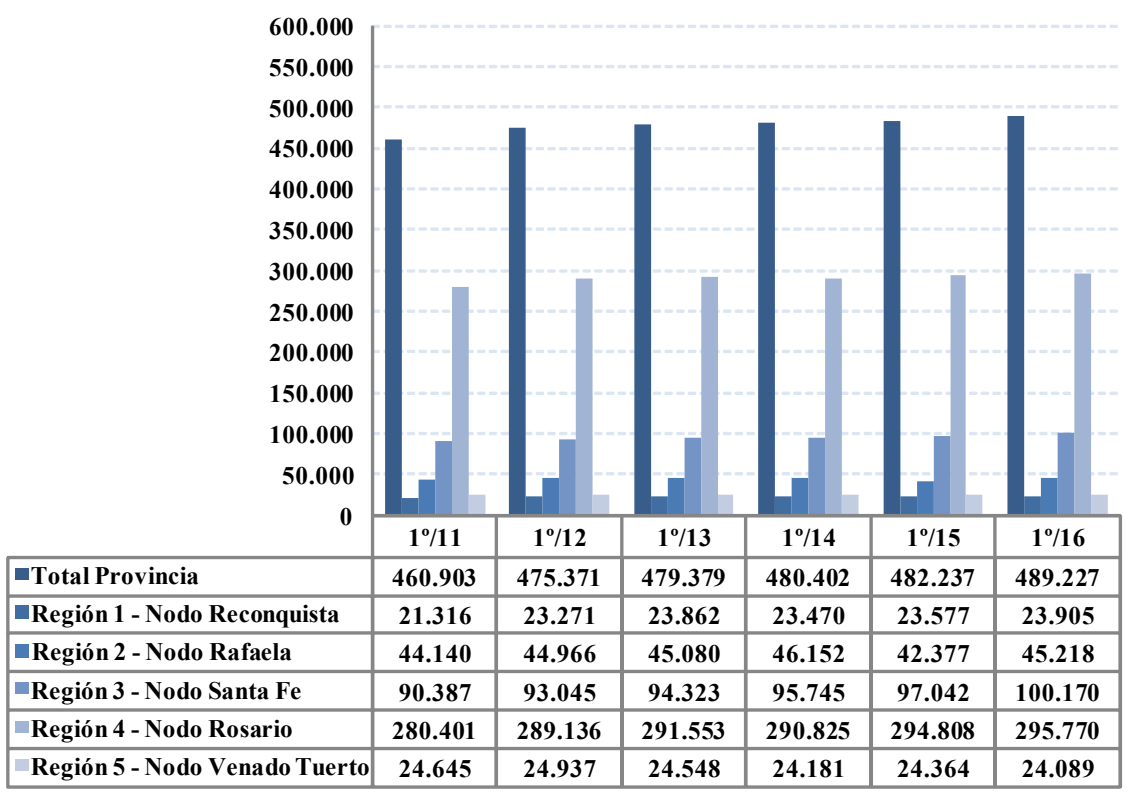


El Gráfico $\mathrm{N}^{\circ} 4$ muestra las variaciones porcentuales interanuales de empleo asalariado registrado. Las regiones 3, 4 y 5 evolucionaron en igual tendencia que la evolución agregada provincial, perdiendo intensidad en su expansión. La Región 1 mostró un fuerte pico de crecimiento en 2012 mientras que la Región 2 tuvo una importante caída en 2015 (compensada con la recuperación de 2016).

\section{Gráfico $N^{0} 4$. Variación porcentual del empleo asalariado registrado por empresas del sector privado. Provincia de Santa Fe y regiones administrativas. $1^{\circ}$ trimestre $2011-1^{\circ}$ trimestre 2016}

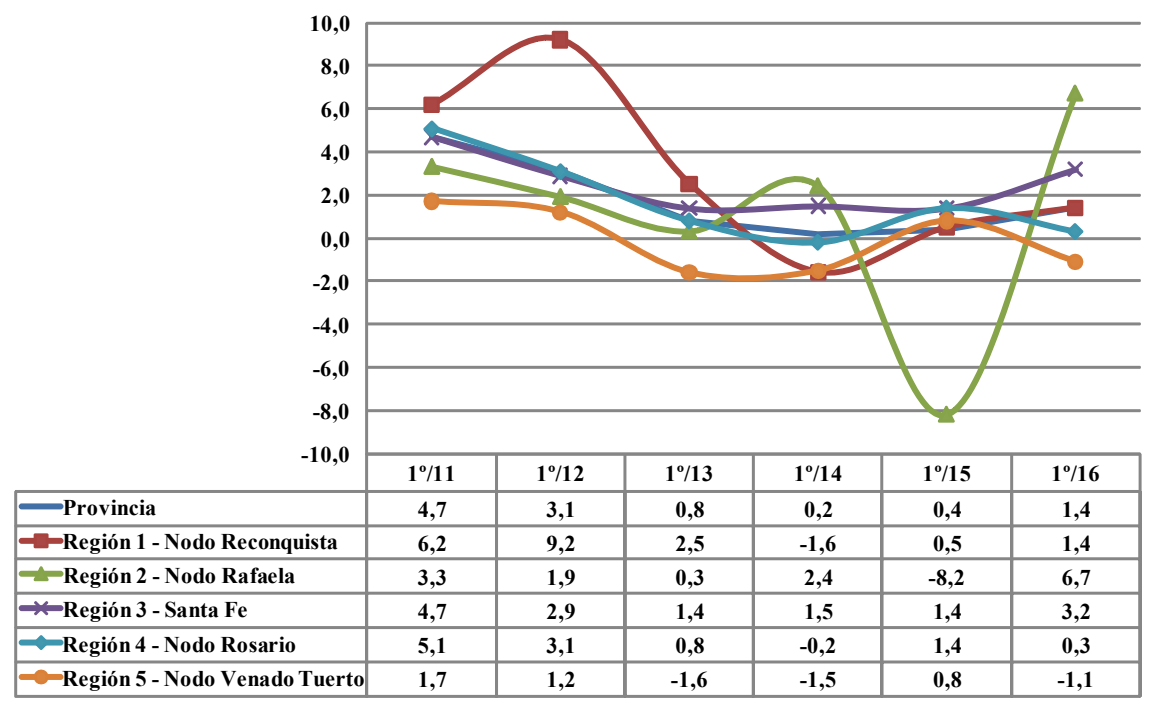

Fuente: Elaboración propia en base a MTySS de la Provincia de Santa Fe en base a SIPA.

La distribución del empleo asalariado registrado según actividades económicas (Tablas $\mathrm{N}^{\circ} 5$ a $\mathrm{N}^{\circ}$ 9) fue, en el $1^{\circ}$ trimestre de 2016, variada según las regiones. Industria manufacturera tuvo un alto peso en las regiones 1 y $2(36,7 \%$ y $37,7 \%$ respectivamente) mientras que en las regiones 3,4 y 5, su incidencia se acercó más al valor del agregado provincial (en torno al 25\%). Agricultura y ganadería perdió peso particularmente en las regiones $1(-22,9 \%)$ y $5(-13,2 \%)$, en las que justamente tienen una alta participación en la composición del empleo asalariado registrado. Comercio se mantuvo sin cambios en las regiones 1,2 y 5 y bajó en las regiones 3 y 4 . Enseñanza aumentó en todas las regiones. Construcción tuvo un ligero crecimiento en las regiones 2,3 y 5 aunque cayó en la 4 y la 1 . Servicios de transporte y almacenamiento cayó en las regiones 1,2 y 5 y aumentó en la 3 y 4 . 
Tabla $N^{0}$ 5. Distribución porcentual del empleo asalariado registrado por empresas del sector privado según sector de actividad económica. Región 1. $1^{\circ}$ trimestre $2011-1^{\circ}$ trimestre 2016

\begin{tabular}{|c|c|c|c|c|c|c|}
\hline \multicolumn{7}{|c|}{ Región 1 - Nodo Reconquista } \\
\hline Actividades económicas & $1^{\circ} / 11$ & $1^{0} / 12$ & $1^{\circ} / 13$ & $1^{\circ} / 14$ & $1^{\circ} / 15$ & $1^{\circ} / 16$ \\
\hline Datos sin especificar & 0,1 & 0,1 & 0,1 & 0,1 & 0,1 & 0,2 \\
\hline $\begin{array}{l}\text { Agricultura, ganadería, } \\
\text { caza, silvicultura y pesca }\end{array}$ & 12,2 & 12,4 & 12,0 & 11,0 & 10,8 & 9,4 \\
\hline $\begin{array}{l}\text { Explotación de minas y } \\
\text { canteras }\end{array}$ & 0,0 & 0,0 & 0,0 & 0,0 & 0,0 & 0,0 \\
\hline Industria manufacturera & 32,4 & 35,0 & 36,3 & 37,0 & 36,4 & 36,7 \\
\hline \begin{tabular}{|l|} 
Suministro de electricidad, \\
gas, vapor y aire \\
acondicionado
\end{tabular} & 0,5 & 0,4 & 0,5 & 0,4 & 0,4 & 0,3 \\
\hline $\begin{array}{l}\text { Suministro de agua, } \\
\text { cloacas, gestión de residuos }\end{array}$ & 0,2 & 0,2 & 0,2 & 0,1 & 0,1 & 0,1 \\
\hline Construcción & 5,2 & 4,7 & 3,9 & 3,8 & 4,4 & 4,5 \\
\hline $\begin{array}{l}\text { Comercio al por mayor y al } \\
\text { por menor }\end{array}$ & 21,0 & 21,0 & 20,8 & 21,7 & 21,3 & 21,6 \\
\hline $\begin{array}{l}\text { Servicio de transporte y } \\
\text { almacenamiento }\end{array}$ & 7,4 & 7,2 & 7,0 & 6,7 & 6,9 & 6,8 \\
\hline $\begin{array}{l}\text { Servicios de alojamiento y } \\
\text { servicios de comida }\end{array}$ & 0,9 & 0,9 & 1,0 & 1,1 & 1,0 & 0,9 \\
\hline $\begin{array}{l}\text { Información y } \\
\text { comunicaciones }\end{array}$ & 1,0 & 0,9 & 0,9 & 0,9 & 0,8 & 0,9 \\
\hline $\begin{array}{l}\text { Intermediación financiera y } \\
\text { servicios de seguros }\end{array}$ & 0,1 & 0,1 & 0,1 & 0,1 & 0,1 & 0,1 \\
\hline Servicios inmobiliarios & 0,2 & 0,2 & 0,3 & 0,3 & 0,1 & 0,2 \\
\hline $\begin{array}{l}\text { Servicios profesionales, } \\
\text { científicos y técnicos }\end{array}$ & 2,1 & 2,2 & 1,8 & 1,8 & 1,4 & 1,2 \\
\hline $\begin{array}{l}\text { Actividades administrativas } \\
\text { y servicios de apoyo }\end{array}$ & 2,6 & 1,5 & 1,7 & 1,6 & 1,4 & 1,3 \\
\hline Enseñanza & 7,9 & 7,4 & 7,5 & 7,9 & 9,7 & 10,6 \\
\hline $\begin{array}{l}\text { Salud humana y servicios } \\
\text { sociales }\end{array}$ & 3,4 & 3,1 & 3,3 & 3,1 & 2,7 & 2,8 \\
\hline $\begin{array}{l}\text { Servicios artísticos, } \\
\text { culturales, deportivos y de } \\
\text { esparcimiento }\end{array}$ & 0,4 & 0,4 & 0,5 & 0,4 & 0,3 & 0,4 \\
\hline $\begin{array}{l}\text { Servicios de asociaciones y } \\
\text { servicios personales }\end{array}$ & 2,4 & 2,3 & 2,1 & 2,0 & 2,1 & 2,0 \\
\hline \begin{tabular}{|l|} 
Servicios de organizaciones \\
y órganos extraterritoriales
\end{tabular} & 0,0 & 0,0 & 0,0 & 0,0 & 0,0 & 0,0 \\
\hline Total & 100,0 & 100,0 & 100,0 & 100,0 & 100,0 & 100,0 \\
\hline
\end{tabular}


Tabla $\mathbf{N}^{0}$ 6. Distribución porcentual del empleo asalariado registrado por empresas del sector privado según sector de actividad económica. Región 2. $1^{\circ}$ trimestre $2011-1^{\circ}$ trimestre 2016

\begin{tabular}{|c|c|c|c|c|c|c|}
\hline \multicolumn{7}{|c|}{ Región 2 - Nodo Rafaela } \\
\hline Actividades económicas & $1^{0} / 11$ & $1^{\circ} / 12$ & $1^{\circ} / 13$ & $1^{\circ} / 14$ & $1^{\circ} / 15$ & $1^{\circ} / 16$ \\
\hline Datos sin especificar & 0,1 & 0,1 & 0,1 & 0,1 & 0,3 & 0,4 \\
\hline $\begin{array}{l}\text { Agricultura, ganadería, caza, } \\
\text { silvicultura y pesca }\end{array}$ & 9,9 & 10,2 & 10,3 & 10,2 & 10,8 & 9,8 \\
\hline $\begin{array}{l}\text { Explotación de minas y } \\
\text { canteras }\end{array}$ & 0,0 & 0,0 & 0,0 & 0,0 & 0,0 & 0,0 \\
\hline Industria manufacturera & 38,3 & 37,5 & 36,3 & 37,0 & 36,0 & 37,7 \\
\hline $\begin{array}{l}\text { Suministro de electricidad, } \\
\text { gas, vapor y aire } \\
\text { acondicionado }\end{array}$ & 0,1 & 0,1 & 0,1 & 0,1 & 0,1 & 0,1 \\
\hline $\begin{array}{l}\text { Suministro de agua, cloacas, } \\
\text { gestión de residuos }\end{array}$ & 0,3 & 0,2 & 0,2 & 0,2 & 0,3 & 0,2 \\
\hline Construcción & 2,2 & 2,6 & 2,2 & 2,1 & 2,4 & 2,4 \\
\hline $\begin{array}{l}\text { Comercio al por mayor y al } \\
\text { por menor }\end{array}$ & 19,8 & 19,5 & 18,9 & 18,8 & 20,4 & 19,9 \\
\hline $\begin{array}{l}\text { Servicio de transporte y } \\
\text { almacenamiento }\end{array}$ & 3,1 & 3,1 & 3,1 & 2,9 & 3,0 & 3,0 \\
\hline $\begin{array}{l}\text { Servicios de alojamiento y } \\
\text { servicios de comida }\end{array}$ & 1,3 & 1,4 & 1,5 & 1,3 & 1,2 & 1,2 \\
\hline Información y comunicaciones & 1,1 & 1,1 & 1,3 & 1,3 & 1,4 & 1,4 \\
\hline $\begin{array}{l}\text { Intermediación financiera y } \\
\text { servicios de seguros }\end{array}$ & 7,8 & 8,1 & 9,5 & 11,0 & 7,2 & 7,9 \\
\hline Servicios inmobiliarios & 0,4 & 0,3 & 0,3 & 0,4 & 0,5 & 0,4 \\
\hline $\begin{array}{l}\text { Servicios profesionales, } \\
\text { científicos y técnicos }\end{array}$ & 2,8 & 3,1 & 2,9 & 2,8 & 2,9 & 2,8 \\
\hline $\begin{array}{l}\text { Actividades administrativas y } \\
\text { servicios de apoyo }\end{array}$ & 1,2 & 1,2 & 1,5 & 1,3 & 1,4 & 1,0 \\
\hline Enseñanza & 3,9 & 3,9 & 4,0 & 4,0 & 5,3 & 5,1 \\
\hline $\begin{array}{l}\text { Salud humana y servicios } \\
\text { sociales }\end{array}$ & 2,8 & 2,5 & 2,4 & 2,3 & 2,5 & 2,5 \\
\hline $\begin{array}{l}\text { Servicios artísticos, culturales, } \\
\text { deportivos y de esparcimiento }\end{array}$ & 0,5 & 0,5 & 0,5 & 0,5 & 0,5 & 0,5 \\
\hline $\begin{array}{l}\text { Servicios de asociaciones y } \\
\text { servicios personales }\end{array}$ & 4,4 & 4,6 & 4,9 & 3,7 & 3,8 & 3,7 \\
\hline $\begin{array}{l}\text { Servicios de organizaciones y } \\
\text { órganos extraterritoriales }\end{array}$ & 0,0 & 0,0 & 0,0 & 0,0 & 0,0 & 0,0 \\
\hline Total & 100,0 & 100,0 & 100,0 & 100,0 & 100,0 & 100,0 \\
\hline
\end{tabular}

Fuente: Elaboración propia en base a MTySS de la Provincia de Santa Fe / SIPA. 
Tabla $\mathbf{N}^{0} 7$. Distribución porcentual del empleo asalariado registrado por empresas del sector privado según sector de actividad económica. Región 3. $1^{\circ}$ trimestre $2011-1^{\circ}$ trimestre 2016

\begin{tabular}{|c|c|c|c|c|c|c|}
\hline \multicolumn{7}{|c|}{ Región 3 - Nodo Santa Fe } \\
\hline Actividades económicas & $1^{0} / 11$ & $1^{\circ} / 12$ & $1^{\circ} / 13$ & $1^{\circ} / 14$ & $1^{0} / 15$ & $1^{\circ} / 16$ \\
\hline Datos sin especificar & 0,2 & 0,3 & 0,2 & 0,1 & 0,1 & 0,7 \\
\hline $\begin{array}{l}\text { Agricultura, ganadería, caza, } \\
\text { silvicultura y pesca }\end{array}$ & 5,0 & 5,2 & 5,1 & 5,1 & 4,8 & 4,6 \\
\hline $\begin{array}{l}\text { Explotación de minas y } \\
\text { canteras }\end{array}$ & 0,2 & 0,1 & 0,1 & 0,1 & 0,1 & 0,1 \\
\hline Industria manufacturera & 22,1 & 21,6 & 21,3 & 21,4 & 20,8 & 20,2 \\
\hline $\begin{array}{l}\text { Suministro de electricidad, } \\
\text { gas, vapor y aire } \\
\text { acondicionado }\end{array}$ & 0,2 & 0,2 & 0,2 & 0,2 & 0,2 & 0,2 \\
\hline $\begin{array}{l}\text { Suministro de agua, cloacas, } \\
\text { gestión de residuos }\end{array}$ & 1,9 & 1,9 & 1,9 & 1,8 & 1,8 & 1,8 \\
\hline Construcción & 6,1 & 6,6 & 6,1 & 6,1 & 6,3 & 6,5 \\
\hline $\begin{array}{l}\text { Comercio al por mayor y al } \\
\text { por menor }\end{array}$ & 23,2 & 23,9 & 23,6 & 23,5 & 22,9 & 22,8 \\
\hline $\begin{array}{l}\text { Servicio de transporte y } \\
\text { almacenamiento }\end{array}$ & 5,5 & 5,3 & 5,4 & 6,4 & 7,3 & 7,0 \\
\hline $\begin{array}{l}\text { Servicios de alojamiento y } \\
\text { servicios de comida }\end{array}$ & 2,8 & 2,8 & 2,8 & 2,7 & 2,7 & 2,7 \\
\hline Información y comunicaciones & 1,4 & 1,2 & 1,3 & 1,1 & 1,1 & 1,0 \\
\hline $\begin{array}{l}\text { Intermediación financiera y } \\
\text { servicios de seguros }\end{array}$ & 3,4 & 3,5 & 3,5 & 3,4 & 3,4 & 3,3 \\
\hline Servicios inmobiliarios & 0,7 & 0,7 & 0,8 & 0,8 & 0,7 & 0,8 \\
\hline $\begin{array}{l}\text { Servicios profesionales, } \\
\text { científicos y técnicos }\end{array}$ & 1,7 & 1,8 & 1,8 & 1,7 & 1,5 & 1,5 \\
\hline $\begin{array}{l}\text { Actividades administrativas y } \\
\text { servicios de apoyo }\end{array}$ & 2,8 & 2,6 & 3,1 & 3,2 & 3,3 & 3,6 \\
\hline Enseñanza & 9,2 & 8,9 & 9,0 & 9,5 & 10,0 & 10,3 \\
\hline $\begin{array}{l}\text { Salud humana y servicios } \\
\text { sociales }\end{array}$ & 4,5 & 4,4 & 4,4 & 4,2 & 4,2 & 4,1 \\
\hline $\begin{array}{l}\text { Servicios artísticos, culturales, } \\
\text { deportivos y de esparcimiento }\end{array}$ & 1,4 & 1,4 & 1,4 & 1,2 & 1,3 & 1,3 \\
\hline $\begin{array}{l}\text { Servicios de asociaciones y } \\
\text { servicios personales }\end{array}$ & 7,7 & 7,6 & 8,0 & 7,5 & 7,5 & 7,5 \\
\hline $\begin{array}{l}\text { Servicios de organizaciones y } \\
\text { órganos extraterritoriales }\end{array}$ & 0,0 & 0,0 & 0,0 & 0,0 & 0,0 & 0,0 \\
\hline Total & 100,0 & 100,0 & 100,0 & 100,0 & 100,0 & 100,0 \\
\hline
\end{tabular}


Tabla $\mathbf{N}^{\circ} 8$. Distribución porcentual del empleo asalariado registrado por empresas del sector privado según sector de actividad económica. Región 4.

$1^{\circ}$ trimestre $2011-1^{\circ}$ trimestre 2016

\begin{tabular}{|c|c|c|c|c|c|c|}
\hline \multicolumn{7}{|c|}{ Región 4 - Nodo Rosario } \\
\hline Actividades económicas & $1^{0} / 11$ & $1^{\circ} / 12$ & $1^{\circ} / 13$ & $1^{\circ} / 14$ & $1^{\circ} / 15$ & $1^{\circ} / 16$ \\
\hline Datos sin especificar & 0,2 & 0,1 & 0,1 & 0,1 & 0,2 & 0,2 \\
\hline $\begin{array}{l}\text { Agricultura, ganadería, caza, } \\
\text { silvicultura y pesca }\end{array}$ & 3,4 & 3,4 & 3,4 & 3,3 & 3,0 & 3,0 \\
\hline $\begin{array}{l}\text { Explotación de minas y } \\
\text { canteras }\end{array}$ & 0,1 & 0,1 & 0,1 & 0,1 & 0,1 & 0,1 \\
\hline Industria manufacturera & 24,0 & 23,8 & 23,6 & 23,5 & 23,1 & 23,2 \\
\hline $\begin{array}{l}\text { Suministro de electricidad, } \\
\text { gas, vapor y aire } \\
\text { acondicionado }\end{array}$ & 0,8 & 0,8 & 0,8 & 0,9 & 0,9 & 0,9 \\
\hline $\begin{array}{l}\text { Suministro de agua, cloacas, } \\
\text { gestión de residuos }\end{array}$ & 1,0 & 0,9 & 1,0 & 1,1 & 1,1 & 1,1 \\
\hline Construcción & 8,4 & 8,7 & 8,1 & 8,1 & 8,2 & 7,7 \\
\hline $\begin{array}{l}\text { Comercio al por mayor y al } \\
\text { por menor }\end{array}$ & 18,0 & 17,8 & 17,8 & 18,1 & 17,6 & 17,7 \\
\hline $\begin{array}{l}\text { Servicio de transporte y } \\
\text { almacenamiento }\end{array}$ & 8,3 & 8,3 & 8,3 & 8,3 & 8,3 & 8,4 \\
\hline $\begin{array}{l}\text { Servicios de alojamiento y } \\
\text { servicios de comida }\end{array}$ & 3,2 & 3,2 & 3,2 & 3,3 & 3,3 & 3,2 \\
\hline Información y comunicaciones & 2,1 & 2,2 & 2,3 & 2,4 & 2,5 & 2,6 \\
\hline $\begin{array}{l}\text { Intermediación financiera y } \\
\text { servicios de seguros }\end{array}$ & 1,7 & 1,7 & 1,7 & 1,8 & 1,8 & 1,6 \\
\hline Servicios inmobiliarios & 0,8 & 0,9 & 0,9 & 0,9 & 0,7 & 0,7 \\
\hline $\begin{array}{l}\text { Servicios profesionales, } \\
\text { científicos y técnicos }\end{array}$ & 1,7 & 1,8 & 1,8 & 1,9 & 1,8 & 1,8 \\
\hline $\begin{array}{l}\text { Actividades administrativas y } \\
\text { servicios de apoyo }\end{array}$ & 8,9 & 8,9 & 9,2 & 8,7 & 9,7 & 9,8 \\
\hline Enseñanza & 6,0 & 6,0 & 6,1 & 6,5 & 6,8 & 7,0 \\
\hline $\begin{array}{l}\text { Salud humana y servicios } \\
\text { sociales }\end{array}$ & 4,6 & 4,7 & 4,9 & 4,9 & 4,9 & 4,9 \\
\hline $\begin{array}{l}\text { Servicios artísticos, culturales, } \\
\text { deportivos y de esparcimiento }\end{array}$ & 1,8 & 1,8 & 1,8 & 1,8 & 1,7 & 1,8 \\
\hline $\begin{array}{l}\text { Servicios de asociaciones y } \\
\text { servicios personales }\end{array}$ & 5,0 & 4,9 & 4,9 & 4,3 & 4,3 & 4,3 \\
\hline $\begin{array}{l}\text { Servicios de organizaciones y } \\
\text { órganos extraterritoriales }\end{array}$ & 0,0 & 0,0 & 0,0 & 0,0 & 0,0 & 0,0 \\
\hline Total & 100,0 & 100,0 & 100,0 & 100,0 & 100,0 & 100,0 \\
\hline
\end{tabular}

Fuente: Elaboración propia en base a MTySS de la Provincia de Santa Fe / SIPA. 
Tabla $\mathbf{N}^{\circ}$ 9. Distribución porcentual del empleo asalariado registrado por empresas del sector privado según sector de actividad económica. Región 5. $1^{\circ}$ trimestre $2011-1^{\circ}$ trimestre 2016

\begin{tabular}{|c|c|c|c|c|c|c|}
\hline \multicolumn{7}{|c|}{ Región 5 - Nodo Venado Tuerto } \\
\hline Actividades económicas & $1^{0} / 11$ & $1^{\circ} / 12$ & $1^{\circ} / 13$ & $1^{\circ} / 14$ & $1^{0} / 15$ & $1^{\circ} / 16$ \\
\hline Datos sin especificar & 0,2 & 0,2 & 0,1 & 0,2 & 0,2 & 0,2 \\
\hline $\begin{array}{l}\text { Agricultura, ganadería, caza, } \\
\text { silvicultura y pesca }\end{array}$ & 15,1 & 14,9 & 14,7 & 14,6 & 14,1 & 13,1 \\
\hline $\begin{array}{l}\text { Explotación de minas y } \\
\text { canteras }\end{array}$ & 0,0 & 0,0 & 0,0 & 0,0 & 0,0 & 0,0 \\
\hline Industria manufacturera & 23,6 & 21,9 & 21,8 & 22,3 & 22,2 & 23,1 \\
\hline $\begin{array}{l}\text { Suministro de electricidad, } \\
\text { gas, vapor y aire } \\
\text { acondicionado }\end{array}$ & 1,7 & 1,6 & 1,6 & 1,8 & 1,7 & 1,7 \\
\hline $\begin{array}{l}\text { Suministro de agua, cloacas, } \\
\text { gestión de residuos }\end{array}$ & 0,5 & 0,5 & 0,5 & 0,5 & 0,5 & 0,5 \\
\hline Construcción & 2,8 & 3,2 & 3,0 & 3,1 & 3,6 & 3,1 \\
\hline $\begin{array}{l}\text { Comercio al por mayor y al } \\
\text { por menor }\end{array}$ & 23,7 & 24,0 & 24,1 & 23,6 & 23,4 & 23,8 \\
\hline $\begin{array}{l}\text { Servicio de transporte y } \\
\text { almacenamiento }\end{array}$ & 6,3 & 6,4 & 6,4 & 5,9 & 5,9 & 5,8 \\
\hline $\begin{array}{l}\text { Servicios de alojamiento y } \\
\text { servicios de comida }\end{array}$ & 1,4 & 1,4 & 1,4 & 1,4 & 1,4 & 1,4 \\
\hline $\begin{array}{l}\text { Información y } \\
\text { comunicaciones }\end{array}$ & 0,8 & 0,8 & 0,8 & 1,1 & 1,1 & 1,2 \\
\hline $\begin{array}{l}\text { Intermediación financiera y } \\
\text { servicios de seguros }\end{array}$ & 1,5 & 1,7 & 1,7 & 1,8 & 1,8 & 1,9 \\
\hline Servicios inmobiliarios & 0,4 & 0,5 & 0,6 & 0,6 & 0,5 & 0,6 \\
\hline $\begin{array}{l}\text { Servicios profesionales, } \\
\text { científicos y técnicos }\end{array}$ & 2,1 & 2,2 & 2,2 & 2,2 & 2,1 & 2,1 \\
\hline $\begin{array}{l}\text { Actividades administrativas y } \\
\text { servicios de apoyo }\end{array}$ & 4,2 & 5,1 & 4,9 & 4,8 & 4,7 & 4,7 \\
\hline Enseñanza & 6,6 & 6,6 & 6,9 & 7,1 & 7,8 & 8,2 \\
\hline $\begin{array}{l}\text { Salud humana y servicios } \\
\text { sociales }\end{array}$ & 2,7 & 2,8 & 3,0 & 2,9 & 2,8 & 2,8 \\
\hline $\begin{array}{l}\text { Servicios artísticos, culturales, } \\
\text { deportivos y de esparcimiento }\end{array}$ & 1,4 & 1,3 & 1,4 & 1,5 & 1,7 & 1,6 \\
\hline $\begin{array}{l}\text { Servicios de asociaciones y } \\
\text { servicios personales }\end{array}$ & 5,0 & 4,9 & 4,9 & 4,6 & 4,5 & 4,2 \\
\hline $\begin{array}{l}\text { Servicios de organizaciones y } \\
\text { órganos extraterritoriales }\end{array}$ & 0,0 & 0,0 & 0,0 & 0,0 & 0,0 & 0,0 \\
\hline Total & 100,0 & 100,0 & 100,0 & 100,0 & 100,0 & 100,0 \\
\hline
\end{tabular}


Según el tamaño de la empresa (Tablas $\mathrm{N}^{\circ} 10$ y No 11 ), a nivel regional se repite lo observado para el total provincial y para los aglomerados GR y GSF: en el $1^{\circ}$ trimestre de 2016, en todas las regiones, las empresas "micro" representaron entre el 74,2\% (Región 4) y el 81,9\% (Región 5) del total de empresas, porcentajes que emplearon entre el 14,1\% (Región 4) y el 24\% (Región 5) del empleo asalariado registrado. En el otro extremo, las empresas "grandes" oscilaron entre el $0,5 \%$ (Región 5 ) y el 1,3\% (Región 4) del total de empresas, absorbiendo entre el $21,8 \%$ (Región 5 ) y el 40,2\% (Región 2) del empleo total. Sintetizando, unas pocas "grandes" empresas tomaron en calidad de registrados a los mayores porcentajes de asalariados mientras que muchas empresas "micro" emplearon menores porcentajes de asalariados registrados.

Tabla $\mathbf{N}^{0} 10$. Distribución porcentual de empresas del sector privado y asalariados registrados según tamaño de la empresa. Provincia de Santa Fe y regiones administrativas. $1^{\circ}$ trimestre 2011

\begin{tabular}{|c|c|c|c|c|c|c|c|c|c|c|c|c|}
\hline \multicolumn{13}{|c|}{$1^{\circ}$ trimestre 2011} \\
\hline Tamaño & Provincia & $\begin{array}{c}\text { Puestos } \\
\text { de tra- } \\
\text { bajo }\end{array}$ & $\begin{array}{c}\text { Región } \\
1\end{array}$ & $\begin{array}{c}\text { Pues- } \\
\text { tos de } \\
\text { trabajo }\end{array}$ & $\begin{array}{c}\text { Región } \\
2\end{array}$ & $\begin{array}{c}\text { Puestos } \\
\text { de tra- } \\
\text { bajo }\end{array}$ & \begin{tabular}{|c} 
Región \\
3
\end{tabular} & $\begin{array}{c}\text { Puestos } \\
\text { de tra- } \\
\text { bajo }\end{array}$ & $\begin{array}{c}\text { Región } \\
4\end{array}$ & $\begin{array}{l}\text { Puestos } \\
\text { de tra- } \\
\text { bajo }\end{array}$ & $\begin{array}{c}\text { Región } \\
5\end{array}$ & $\begin{array}{l}\text { Puestos } \\
\text { de tra- } \\
\text { bajo }\end{array}$ \\
\hline \multirow{2}{*}{$\begin{array}{l}\text { Microe- } \\
\text { mpresas } \\
\text { (1 - 5 asala- } \\
\text { riados) }\end{array}$} & 77,0 & 17,2 & 80,3 & 19,3 & 81,3 & 19,1 & 77,4 & 18,2 & 74,9 & 15,6 & 82,6 & 27,1 \\
\hline & & & & & & & & & & & & \\
\hline \multirow{2}{*}{$\begin{array}{l}\text { Pequeñas } \\
\text { empresas } \\
(6-25 \text { asala- } \\
\text { riados })\end{array}$} & 17,3 & 22,4 & 13,8 & 19,5 & 14,4 & 19,1 & 17,3 & 23,2 & 18,6 & 22,7 & 13,6 & 25,2 \\
\hline & & & & & & & & & & & & \\
\hline \multirow{2}{*}{$\begin{array}{l}\text { Medianas } \\
\text { empresas } \\
(26-100 \\
\text { asalariados })\end{array}$} & 4,7 & 25,3 & 5,1 & 29,8 & 3,5 & 19,7 & 4,2 & 24,1 & 5,3 & 26,2 & 3,3 & 26,4 \\
\hline & & & & & & & & & & & & \\
\hline \multirow{2}{*}{\begin{tabular}{|l|} 
Grandes \\
empresas \\
(Más de 100 \\
asalariados) \\
\end{tabular}} & 1,0 & 35,1 & 0,8 & 31,4 & 0,8 & 42,1 & 1,1 & 34,5 & 1,2 & 35,5 & 0,5 & 21,3 \\
\hline & & & & & & & & & & & & \\
\hline Total & 100,0 & 100,0 & 100,0 & 100,0 & 100,0 & 100,0 & 100,0 & 100,0 & 100,0 & 100,0 & 100,0 & 100,0 \\
\hline
\end{tabular}

Fuente: Elaboración propia en base a MTySS de la Provincia de Santa Fe / SIPA. 
Tabla $\mathbf{N}^{\circ} 11$. Distribución porcentual de empresas del sector privado y asalariados registrados según tamaño de la empresa. Provincia de Santa Fe y regiones administrativas. $1^{\circ}$ trimestre 2016

\begin{tabular}{|c|c|c|c|c|c|c|c|c|c|c|c|c|}
\hline \multicolumn{13}{|c|}{$1^{\circ}$ trimestre 2011} \\
\hline Tamaño & Provincia & $\begin{array}{c}\text { Puestos } \\
\text { de tra- } \\
\text { bajo }\end{array}$ & $\begin{array}{c}\text { Región } \\
1\end{array}$ & \begin{tabular}{|c|} 
Pues- \\
tos de \\
trabajo
\end{tabular} & $\begin{array}{c}\text { Región } \\
2\end{array}$ & $\begin{array}{c}\begin{array}{c}\text { Puestos } \\
\text { de tra- } \\
\text { bajo }\end{array} \\
\end{array}$ & $\begin{array}{c}\text { Región } \\
3\end{array}$ & $\begin{array}{c}\text { Puestos } \\
\text { de tra- } \\
\text { bajo }\end{array}$ & $\begin{array}{c}\text { Región } \\
4\end{array}$ & $\begin{array}{c}\begin{array}{c}\text { Puestos } \\
\text { de tra- } \\
\text { bajo }\end{array} \\
\end{array}$ & $\begin{array}{c}\text { Región } \\
5\end{array}$ & \begin{tabular}{|c}
$\begin{array}{c}\text { Puestos } \\
\text { de tra- } \\
\text { bajo }\end{array}$ \\
\end{tabular} \\
\hline Microe- & & & & & & & & & & & & \\
\hline $\begin{array}{l}(1-5 \\
\text { asalaria- } \\
\text { dos })\end{array}$ & 76,3 & 15,4 & 79,8 & 16,1 & 80,5 & 17,7 & 77,1 & 16,0 & 74,2 & 14,1 & 81,9 & 24,0 \\
\hline Pequeñas & & & & & & & & & & & & \\
\hline $\begin{array}{l}\text { empresas } \\
(6-25 \\
\text { asalaria- } \\
\text { dos })\end{array}$ & 17,5 & 21,1 & 13,9 & 17,4 & 14,4 & 18,3 & 17,2 & 20,8 & 19,0 & 21,6 & 13,8 & 24,6 \\
\hline Medianas & & & & & & & & & & & & \\
\hline $\begin{array}{l}(26-100 \\
\text { asalaria- } \\
\text { dos) }\end{array}$ & 5,0 & 25,4 & 5,4 & 29,7 & 4,3 & 23,8 & 4,5 & 23,8 & 5,5 & 25,6 & 3,8 & 29,6 \\
\hline Grandes & & & & & & & & & & & & \\
\hline $\begin{array}{l}\text { empresas } \\
\text { (Más de } \\
100 \text { asa- } \\
\text { lariados) }\end{array}$ & 1,2 & 38,1 & 0,9 & 36,8 & 0,8 & 40,2 & 1,2 & 39,4 & 1,3 & 38,7 & 0,5 & 21,8 \\
\hline Total & 100,0 & 100,0 & 100,0 & 100,0 & 100,0 & 100,0 & 100,0 & 100,0 & 100,0 & 100,0 & 100,0 & 100,0 \\
\hline
\end{tabular}

Fuente: Elaboración propia en base a MTySS de la Provincia de Santa Fe / SIPA.

\section{Conclusiones}

Procurando compendiar y resumir los principales hallazgos de la caracterización realizada en las páginas precedentes, entre los primeros trimestres de 2011 y 2016, las empresas del sector privado fiscalmente domiciliadas en la provincia de Santa Fe incrementaron en 28.324 el número de ocupaciones asalariadas registradas $(6,1 \%)$. La variación interanual de estos puestos de trabajo, aun positiva, mostró una marcada tendencia a la desaceleración, pasando de crecer $4,7 \%$ en 2011 a 1,4\% en 2016, con un piso de $0,2 \%$ en 2014. A lo largo del período hubo algunos cambios importantes en la distribución del empleo asalariado registrado 
según sectores de actividad económica. Industria manufacturera fue la actividad que más demandó ocupaciones asalariadas registradas, si bien perdió $3,1 \%$ de participación (al igual que Construcción y Agricultura y ganadería, las que perdieron $5,7 \%$ y $13 \%$ ), en un contexto de inflación, crisis en Brasil y carencia de divisas que la apuntalasen. Vale remarcar la expansión de Enseñanza (16,6\%) y Actividades administrativas y servicios de apoyo $(9,4 \%)$. Con respecto a las primeras, no debe descartarse el rol de "refugio" que cumplen en contextos de amesetamiento del empleo. Sobre las segundas, como ya se dijo, se trata de servicios (obtención de personal, servicios de seguridad y limpieza, entre otros) de demanda elástica con respecto a cambios en el nivel de actividad económica. Con respecto a la relación entre tamaño de la empresa y nivel de empleo, hacia el $1^{\circ}$ trimestre de 2016, casi el $40 \%$ de los puestos asalariados registrados lo creó un grupo de 603 empresas que representó apenas el 1,2\% del total de empresas con domicilio fiscal en la provincia. El hecho puede indicar la mayor capacidad de este tipo de firmas para afrontar los costos asociados al registro laboral así como sus menores chances de eludir la fiscalización estatal.

Con matices, estos rasgos se repitieron tanto a nivel de aglomerados como de regiones. En GR, los servicios tuvieron más preponderancia que en GSF en la generación de empleo asalariado registrado, tal como lo demuestra Actividades administrativas y servicios de apoyo (11,4\% en el $1^{\circ}$ trimestre de 2016), sector integrado por ramas sensibles a las oscilaciones de la demanda. Esta mayor diversificación del aparato productivo no deja de representar una potencial fortaleza en períodos económicamente recesivos. GR también se caracterizó por contar con una mayor presencia de empresas "pequeñas" y "medianas" que lo informado por el agregado provincial y GSF (más polarizados en empresas "micro" y "grandes”), hecho que puede interpretarse como favorable, evitando una menor exposición relativa a los vaivenes de pocas grandes empresas. Las "pequeñas" aportaron poco más del 20\% del empleo asalariado registrado y las segundas, casi el $25 \%$. Por su parte, en GSF el menor peso de Industria manufacturera lo compensó Comercio (aun perdiendo participación a lo largo del período), Enseñanza y Servicios de asociaciones y servicios personales. Otra particularidad de este aglomerado fue, como se acaba de apuntar, la concentración del empleo registrado $(43,3 \%)$ en empresas "grandes".

En el plano de las regiones, en el $1^{\circ}$ trimestre de 2011 la 5 (Nodo Venado Tuerto) era la anteúltima en términos de participación porcentual en el empleo privado formal total mientras que en el $1^{\circ}$ trimestre de 2016 fue alcanzada por la Región 1 (Nodo Reconquista). La Región 5, de fuerte impronta agropecuaria y metalmecánica, fue la única que perdió puestos de trabajo.

De acuerdo a lo señalado, los cambios en la composición según sector de actividad económica del empleo asalariado registrado fueron menores. En la Región 1 (Nodo Reconquista), Agricultura y ganadería perdió participación pero Industria manufacturera y Enseñanza la ganaron. En la Región 2 (Nodo Rafaela) prácticamente no hubo modificaciones entre los primeros trimestres de 2011 y 2016 . En estas dos regiones, la fuerte concentración del empleo asalariado registrado en 
Industria manufacturera (con valores cercanos al 40\%) marca al Estado provincial y a los Estados locales un área de intervención en pos de estimular un tejido productivo más diversificado y menos dependiente de otros centros urbanos en cuanto a servicios. En la Región 3 (Nodo Santa Fe), la caída de Industria manufacturera fue morigerada por las alzas en servicios (Enseñanza, Servicios de transporte y almacenamiento y Actividades administrativas y servicios de apoyo). En la Región 4 (Nodo Rosario), algo similar: las bajas en Agricultura y ganadería y Construcción fueron compensadas por subas en Enseñanza y Actividades administrativas y servicios de apoyo. En la Región 5 cayeron Agricultura y ganadería $(13,2 \%)$ y Servicios de transporte y almacenamiento (actividad vinculada a la anterior, 8\%) mientras subió Enseñanza e Intermediación financiera y servicios de seguros.

Se observa, por último, que en las regiones 1,2 y 5 (las de menor volumen de empleo asalariado formal) primaron las empresas "micro", si bien las "grandes" - porcentualmente menos que en las regiones 3 y 4 - emplearon los mayores porcentajes de asalariados registrados (con excepción de la Región 5). El rasgo refuerza la atención que en términos de políticas públicas focalizadas merecen las unidades productivas de la escala "micro", cuya supervivencia, consolidación y crecimiento en el tiempo es clave para apuntalar el empleo asalariado.

La evolución del empleo asalariado registrado privado en la provincia de Santa Fe ha mostrado en los últimos años ser sensible a la dinámica general de la actividad productiva provincial y nacional. Si bien actualmente crece a tasas muy bajas, el desempeño de años anteriores permite mantener el moderado optimismo de que las relaciones salariales "verdaderas", "típicas", "fordistas" que organizan la producción capitalista, antes que tender a extinguirse por costosas, anticompetitivas o por cambios en las preferencias de los individuos hacia el trabajo independiente, necesitan el despliegue de un ciclo de crecimiento económico sostenido en el tiempo. ¿Hay tarea más política que construir sus condiciones de posibilidad?

\section{Referencias}

1. Se sigue la definición de empleo propuesta por Neffa, quien lo considera trabajo que se hace "para obtener a cambio un ingreso, en calidad de asalariado, de empleador, o actuando por su propia cuenta [...] El mismo puede desenvolverse en el ámbito mercantil o en actividades sin fines de lucro y llevarse a cabo sin relación de dependencia o como asalariado" (Neffa, 2014: 11).

2. Esta dependencia es triple. En primer término, el trabajador se ajusta al derecho de dirección del empleador, cuya autoridad funcional debe obedecer (dependencia jurídica). En segundo lugar, el trabajador presta servicios a cuenta del beneficio del empleador (dependencia económica). Por último (dependencia técnica), el trabajador se adecua a los procedimientos y las modalidades de ejecución de tareas que fija su empleador (Ministerio de Trabajo, Empleo y Seguridad Social, 2014, en adelante MTEySS).

3. Sea por tiempo indeterminado, por temporada, eventual, a plazo fijo o por equipo (Ley de Contrato de Trabajo N ${ }^{\circ}$ 20.744).

4. Fuerzas asimétricas dada la disponibilidad por parte de los empleadores -al momento de acordar contratos de trabajo- de un mayor número de alternativas estratégicas que las disponibles para los trabajadores asalariados (Offe y Hinrichs, 1992).

5. En Argentina, el MTEySS define al Sistema de Seguridad Social como "el conjunto de regímenes y normas adoptadas por el Estado que tiene como objetivo mantener el nivel de vida de la población y 
asistir a los necesitados mediante prestaciones en dinero y servicios, cuando son afectados por contingencias consideradas socialmente protegibles" (Administración Nacional de la Seguridad Social, 2011: 15). De acuerdo con Curcio, este sistema provee certidumbre y asegura a las personas "frente al riesgo de pérdidas de ingresos o shock de gastos asociados con el retiro en la vejez, invalidez, enfermedad, accidentes, fallecimiento o situación de desempleo" (2011: 33). El Sistema de Seguridad Social se compone por 1) el Sistema Único de Seguridad Social (integrado por los subsistemas a. previsional -SIPA, ley $\mathrm{N}^{\mathrm{o}} 26.425 / 08-;$ b. de asignaciones familiares -ley $\mathrm{N}^{\circ} 24.714 / 96-$; c. de desempleo -ley $\mathrm{N}^{\mathrm{o}} 24.013 / 91-;$ de riesgos del trabajo -ley $\mathrm{N}^{\mathrm{o}} 24.557 / 95-$ y 2) por el Sistema Nacional del Seguro de Salud (integrado por el Instituto Nacional de Servicios Sociales para Jubilados y Pensionados - ley $^{\circ}$ 19.032/71-y por las obras sociales nacionales -ley No 23.660/89-) (Curcio, 2011).

6. En años recientes, el fomento a tales "empleos típicos" contó con la sanción de leyes como la $\mathrm{N}^{\circ}$ 25.877/04 ("Ordenamiento del régimen laboral y promoción del empleo") y la No 26.476/08 ("Régimen de regularización del empleo no registrado y promoción y protección del empleo registrado") tendientes a reducir contribuciones patronales en casos de contratación de mano de obra.

7. El empleo asalariado "en negro", tal como se conoce popularmente al empleo asalariado no registrado ante las agencias estatales vinculadas al Sistema de Seguridad Social, representa la máxima desprotección para el trabajador y su familia ya que, formalmente (de jure), el vínculo laboral con el empleador no existe.

8. El empleo precario es aquel que se caracteriza por su "debilidad en cuanto a la permanencia de la relación salarial de dependencia, con sus implicancias jurídicas y económicas en materia de estabilidad así como de protección legal y de seguridad social" (Neffa, 2014: 41). Esta definición comprende asalariados no registrados, asalariados fraudulentos y contratados por tiempo determinado, a jornada parcial y por agencias de empleo.

9. En igual período $\left(1^{\circ}\right.$ trimestre de $2004 / 1^{\circ}$ trimestre de 2011$)$, en GR, los asalariados pasaron del $68,8 \%$ al $75,9 \%$ del total de ocupados mientras que en GSF esta participación no se modificó $(73,4 \%$ y $73,8 \%$ ). Estimación propia en base a microdatos de la Encuesta Permanente de Hogares (EPH)INDEC.

10. El SC no brinda información referida a asalariados no registrados - sin descuento jubilatorio-, trabajadores independientes - cuentapropistas y patrones-, trabajadores familiares sin remuneración, empleados del Estado y servicio doméstico, aspectos en cambio sí relevados por la EPH y la EAHU.

11. En sentido estricto, de acuerdo al informe "Indicadores socioeconómicos" de la EPH, en el $1^{\circ}$ trimestre de 2015 (último dato disponible para el período abordado en este trabajo), el porcentaje de asalariados sin descuento jubilatorio fue $30,2 \%$ en Gran Rosario y $28,7 \%$ en Gran Santa Fe (INDEC, 2015).

12. Dicha nota metodológica explica que los empleadores pueden declarar domicilio fiscal en la Provincia de Santa Fe aunque el establecimiento productivo opere, de hecho, fuera de ella. En estos casos, el SC acarrea dos sesgos: a) contabiliza como ocupados santafesinos trabajadores que residen en otra provincia y b) no contabiliza como empleo santafesino la mano de obra provincial en relación de dependencia con empresas que operan en la provincia pero tienen domicilio fiscal fuera de ella. A modo de ejemplo, los trabajadores de una empresa instalada en la Provincia de Santa Fe cuyo domicilio fiscal radica en provincia de Buenos Aires no son contabilizados como ocupados santafesinos y sí son contabilizados como tales los trabajadores de una empresa con domicilio fiscal en la Provincia de Santa $\mathrm{Fe}$ pero instalada en provincia de Buenos Aires.

13. El aglomerado GSF incluye las siguientes localidades: Santa Fe, Santo Tomé, Sauce Viejo, Recreo, Arroyo Leyes y San José del Rincón.

14. Las localidades incluidas en el aglomerado GR son Rosario, Funes, Soldini, Pérez, Villa Gobernador Gálvez, Puerto General San Martín, San Lorenzo, Granadero Baigorria, Capitán Bermúdez, Fray Luis Beltrán y Roldán.

15. La Región 1 tiene por ciudad nodo a Reconquista e incluye localidades de los departamentos Vera, General Obligado y San Javier. La Región 2, con nodo en la ciudad de Rafaela, abarca localidades de los departamentos Castellanos, 9 de Julio, San Cristóbal y San Martín. La Región 3 (nodo en Santa Fe) comprende localidades de los departamentos San Justo, sur de San Javier, Garay, Las Colonias, La Ca- 
pital y parte de San Jerónimo. La Región 4, nodo en Rosario, hace lo propio con los departamentos San Martín (sur), parte de San Jerónimo, Belgrano, Iriondo, San Lorenzo, parte de Caseros, Rosario y parte de Constitución. Por último, la Región 5 tiene por ciudad nodal a Venado Tuerto y reúne localidades de los departamentos General López, parte de Caseros y parte de Constitución.

16. Para más información sobre el PEP y el proceso de regionalización iniciado en 2008 y financiado parcialmente por Urb-Al III, consultar Provincia de Santa Fe (2008).

17. El PIB creció en el período 2011-2014 pero mermando su dinámica: 8,4\%, 0,8\%, 2,9\% y 0,5\% (Banco Mundial, 2016). Para la Comisión Económica para América Latina y el Caribe (CEPAL), los valores fueron ligeramente diferentes: $6 \%$ (2011), $-1 \%$ (2012), 2,4\% (2013), $-2,5 \%$ (2014) у 2,5\% (2015) (CEPAL, 2016).

18. Por cuestiones de espacio no se desarrollan aquí las distintas interpretaciones que explican las causas del alza en los precios internos.

19. La soja -sembrado que ocupa el $30 \%$ de la superficie de la Provincia de Santa Fe- alcanzó una cotización cercana a los US\$600 hacia fines de 2008 y tuvo un precio fluctuante en 2009 y 2010, ubicándose por entonces en torno a los US\$350.

20. Estimación propia para el total de aglomerados urbanos en base a microdatos de la EPH-INDEC. A la fecha, los microdatos correspondientes al $1^{\circ}$ trimestre de 2016 no han sido publicados por el INDEC.

21. Para profundizar sobre los detalles de este proceso recesivo iniciado en Estados Unidos con una crisis financiera y luego expandido hacia otras economías consultar Machinea (2009) y Krugman (2012). 22. Agricultura y ganadería aportó $8,9 \%$ del PBG de 2015 , Industria manufacturera $18,9 \%$, Comercio $16 \%$ y Servicios $24 \%$ (Provincia de Santa Fe, 2016b). Entre otros rasgos, cabe mencionar que el territorio santafesino alberga el polo exportador agroindustrial aceitero y cerealero más grande del mundo (emplazado en las localidades de Puerto General San Martín, Timbúes y San Lorenzo), un importante complejo metalmecánico (Las Parejas, Firmat) y dos de las principales cuencas lecheras de Sudamérica (cuencas Centro y Sur).

23. A modo de ejemplo, para agosto de 2014, en la Provincia de Santa Fe el número de trabajadores beneficiados con REPRO se ubicó entre 5.800 y 6.000 (Diario Uno Santa Fe, 2014).

24. Estimación propia en base a microdatos de la EPH-INDEC.

\section{Bibliografía}

ADMINISTRACIÓN NACIONAL DE LA SEGURIDAD SOCIAL (2011), Marco conceptual del sistema de estadísticas e indicadores del Sistema Integrado Previsional Argentino. Disponible en: http:// observatorio.anses.gob.ar/archivos/documentos/Cuadernillo_MARCO\%20CONCEPTUAL.pdf. Fecha de consulta: 31/05/17.

BANCO MUNDIAL (2016), Indicadores del desarrollo mundial. Disponible en: http://datos.bancomundial.org/indicador/NY.GDP.MKTP.KD.ZG?locations=AR. Fecha de consulta: 07/08/16.

L. BECCARIA y P. GALÍN (2002), Regulaciones laborales en Argentina. Evaluaciones y propuestas, Buenos Aires, Fundación OSDE-CIEPP.

F. BERTRANOU y L. CASANOVA (2014), Informalidad laboral en Argentina. Segmentos criticos y politicas para la formalización, Buenos Aires, OIT.

M. BUSSO y P. PÉREZ (2010), "Introducción”, en P. PÉREZ y M. BUSSO (Coords.), La corrosión del trabajo. Estudios sobre informalidad y precariedad laboral, Buenos Aires, Miño y Dávila.

R. CASTEL (1997), La metamorfosis de la cuestión social: una crónica del salariado, Buenos Aires, Paidós.

R. CASTEL (2004), La inseguridad social. ¿Qué es estar protegido?, Buenos Aires, Manantial. CENTRO DE ESTUDIOS PARA EL DESARROLLO ARGENTINO (2012), La anatomía del nuevo patrón de crecimiento y la encrucijada actual. La economía argentina en el periodo 2002-2010, Buenos Aires, Cara o Ceca.

COMISIÓN ECONÓMICA PARA AMÉRICA LATINA Y EL CARIBE (2016), Argentina: perfil nacional económico. Disponible en: http://interwp.cepal.org/cepalstat/Perfil_Nacional_Economico. html?pais=ARG\&idioma=spanish. Fecha de consulta: 02/06/17. 
R. CORTÉS y A. MARSHALL (1991), "Estrategias económicas, intervención social del Estado y regulación de la fuerza de trabajo", en Estudios del Trabajo, Buenos Aires, $\mathrm{N}^{\circ} 1$.

J. CURCIO (2011), “ Descripción del Sistema de Seguridad Social: componentes al cabo de la década del ' 90 y de la primera década del siglo XXI", en C. DANANI y S. HINTZE (Coords.), Protecciones y desprotecciones: la seguridad social en la Argentina 1990/2010, Los Polvorines, Universidad Nacional de General Sarmiento.

M. DAMILL y R. FRENKEL (2015), "La economía argentina bajo los Kirchner: una historia de dos lustros”, en C. GERVASONI y E. PERUZZOTTI (Eds.), ¿Década ganada? Evaluando el legado del kirchnerismo, Buenos Aires, Debate.

DIARIO UNO SANTA FE (2014), "En la Provincia de Santa Fe son cerca de 6.000 los beneficiarios de Repro". Disponible en: http://www.unosantafe.com.ar/en-la-provincia-santa-fe-son-cerca-6000-losbeneficiarios-repro-n855435. Fecha de consulta: 12/08/16.

FEDERACIÓN INDUSTRIAL DE SANTA FE (2014), Informe de actualidad industrial de Santa Fe, diciembre, $N^{\circ}$ 32. Disponible en: http://www.fisfe.com-/economia.php?id_pag=2\&id_sec=47. Fecha de consulta: 12/08/16.

S.FELDMAN y P. GALÍN (1990), "Nota introductoria", en P. GALÍN y M. NOVICK (Comps.), La precarización del empleo en la Argentina, Buenos Aires, CEAL, CIAT-OIT, CLACSO.

A. GORZ (1981), Adiós al proletariado: más allá del socialismo, Barcelona, Viejo Topo.

INSTITUTO NACIONAL DE ESTADÍSTICA Y CENSOS (2003), La nueva Encuesta Permanente de Hogares de Argentina. 2003. Disponible en: http://www.indec.gov.ar/ftp/cuadros/sociedad/Metodologia_EPHContinua.pdf. Fecha de consulta: 06/08/16.

INSTITUTO NACIONAL DE ESTADÍSTICA Y CENSOS (2015), Encuesta Permanente de Hogares. Indicadores socioeconómicos. Resultados del primer trimestre 2015. Disponible en: http://www.indec. mecon.ar/uploads/informesdeprensa/indicadores_eph_1trim15.pdf. Fecha de consulta: 08/08/16.

P. KRUGMAN (2012), ;Acabad ya con esta crisis!, Barcelona, Crítica Editorial.

M. KULFAS (2016), Los tres kirchnerismos. Una historia de la economía argentina 2003-2015, Buenos Aires, Siglo Veintiuno.

J. LINDENBOIM, L. SERINO y M. GONZÁLEZ (2000), "La precariedad como forma de exclusión", en Cuadernos del CEPED, $\mathrm{N}^{\circ}$ 4, Buenos Aires, FCE-UBA.

J. L. MACHINEA (2009), "La crisis financiera internacional: su naturaleza y los desafíos de política económica”, Revista CEPAL, No 97, México, CEPAL.

D. MÉDA (1998), El trabajo: un valor en peligro de extinción, Buenos Aires, Gedisa.

MINISTERIO DE TRABAJO, EMPLEO Y SEGURIDAD SOCIAL (2014), Guía de orientación para la contratación de trabajadores. Disponible en: http://www.trabajo.gob.ar/downloads/infoutil/Guia Contrataciones.pdf. Fecha de consulta: 05/08/16.

MINISTERIO DE TRABAJO, EMPLEO Y SEGURIDAD SOCIAL (2016), Programa de Recuperación Productiva. Disponible en: http://www.trabajo.gov.ar/prp/. Fecha de consulta: 12/08/16.

R. MIZRAHI (1989), "Las condiciones fundacionales del sector informal urbano", en Desarrollo Económico, $\mathrm{N}^{\circ} 112$, Buenos Aires, IDES.

A. MONZA (2002), Los dilemas de la política de empleo en la coyuntura argentina actual, Buenos Aires, CIEPP-OSDE.

J. C. NEFFA (2008), "Empleo informal, trabajo no registrado y trabajo precario. Dimensiones teóricas y conceptuales", en J. C. NEFFA (Coord.), La informalidad, la precariedad laboral y el empleo no registrado en la Provincia de Buenos Aires, Buenos Aires, Ministerio de Trabajo de la Provincia de Buenos Aires - CEIL- PIETTE CONICET.

J. C. NEFFA (2010), "Naturaleza y significación del trabajo/empleo precario", en M. BUSSO y P. PÉREZ (Coords.), La corrosión del carácter. Estudios sobre informalidad y precariedad laboral, Buenos Aires, Miño y Dávila - CEIL-PIETTE CONICET.

J. C. NEFFA (2014), Actividad, empleo y desempleo. Conceptos y definiciones, Buenos Aires, CEIL PIETTE CONICET.

C. OFFE y K. HINRICHS (1992), "Economía social del mercado de trabajo: los desequilibrios de poder primario y secundario", en C. OFFE, La sociedad del trabajo, Madrid, Alianza Universidad. 
PROVINCIA DE SANTA FE (2008), Plan Estratégico Provincial. Disponible en: http://www.santafe. gov.ar/index.php/plan_estrategico_provincial. Fecha de consulta: 08/08/16.

PROVINCIA DE SANTA FE (2014a), Nota metodológica. Disponible en: http://www.santafe.gov.ar. Fecha de consulta: 08/08/16.

PROVINCIA DE SANTA FE (2014b), Clasificador de Actividades Económicas (Formulario AFIP $N^{o}$ 883). Disponible en: http://www.santafe.gov.ar. Fecha de consulta: 03/06/17.

PROVINCIA DE SANTA FE (2016a), Producto Geográfico Bruto a precios constantes de 1993 según categoria. Variaciones anuales, en porcentaje. Provincia de Santa Fe. Periodo 1993-2015. Disponible en: https://www.santafe.gov.ar. Fecha de consulta: 11/08/16.

PROVINCIA DE SANTA FE (2016b), Producto Geográfico Bruto a precios constantes de 1993 según categoría. Provincia de Santa Fe. Periodo 1993-2015. Disponible en: https://www.santafe.gov.ar. Fecha de consulta: 11/08/16.

J. RIFKIN (1995), El fin del trabajo. Nuevas tecnologías contra puestos de trabajo: el nacimiento de una nueva era, México, Paidós.

M. SCHORR (2012), “Argentina: ¿nuevo modelo o 'viento de cola'? Una caracterización en clave comparativa", en Nueva Sociedad, $\mathrm{N}^{\circ} 237$, Buenos Aires, Fundación Ebert.

V. TOKMAN (1991), "Introducción: dos décadas de sector informal en América Latina", en V. TOKMAN (Comp.), El sector informal en América Latina. Dos décadas de análisis, México, Consejo Nacional para la Cultura y las Artes.

UNIVERSIDAD CATÓLICA ARGENTINA (2016), Estructura social del trabajo y calidad de las inserciones laborales en la Argentina (2010-2015). Desafios para las actuales políticas sociales y de empleo, Buenos Aires, Observatorio de la Deuda Social.

Recibido: 17/08/2016. Aceptado: 11/07/2017.

Martín Carné, “El empleo asalariado registrado creado en la Provincia de Santa Fe por empresas del sector privado: atributos y dinámica reciente (2011-2016)". Revista Temas y Debates. ISSN 1666-0714, año 21, número 34, julio-diciembre 2017, pp. 127-155. 